\title{
Imaging of Multiple Sclerosis: Role in Neurotherapeutics
}

\author{
Rohit Bakshi,* Alireza Minagar, ${ }^{\dagger}$ Zeenat Jaisani,* and Jerry S. Wolinsky ${ }^{\ddagger}$ \\ *Departments of Neurology and Radiology, Partners MS Center, Center for Neurological Imaging, Brigham and Women's \\ Hospital, Harvard Medical School, Boston, Massachusetts 02115; ${ }^{\dagger}$ Department of Neurology, Louisiana State University Health \\ Sciences Center, Shreveport, Louisiana 71130; and ${ }^{\star}$ Department of Neurology, University of Texas Health Science Center at \\ Houston, Houston, Texas 77030
}

Summary: Magnetic resonance imaging (MRI) plays an everexpanding role in the evaluation of multiple sclerosis (MS). This includes its sensitivity for the diagnosis of the disease and its role in identifying patients at high risk for conversion to MS after a first presentation with selected clinically isolated syndromes. In addition, MRI is a key tool in providing primary therapeutic outcome measures for phase I/II trials and secondary outcome measures in phase III trials. The utility of MRI stems from its sensitivity to longitudinal changes including those in overt lesions and, with advanced MRI techniques, in areas affected by diffuse occult disease (the so-called normalappearing brain tissue). However, all current MRI methodology suffers from limited specificity for the underlying histopathology. Conventional MRI techniques, including lesion detection and measurement of atrophy from T1- or T2-weighted images, have been the mainstay for monitoring disease activity in clinical trials, in which the use of gadolinium with T1-weighted images adds additional sensitivity and specificity for areas of acute inflammation. Advanced imaging methods including magnetization transfer, fluid attenuated inversion recovery, diffusion, magnetic resonance spectroscopy, functional MRI, and nuclear imaging techniques have added to our understanding of the pathogenesis of MS and may provide methods to monitor therapies more sensitively in the future. However, these advanced methods are limited by their cost, availability, complexity, and lack of validation. In this article, we review the role of conventional and advanced imaging techniques with an emphasis on neurotherapeutics. Key Words: Multiple sclerosis, magnetic resonance imaging, brain atrophy, diffusion imaging, magnetization transfer, spectroscopy, functional imaging.

\section{INTRODUCTION}

Since introduced into clinical medicine, magnetic resonance imaging (MRI) has played expanding roles in the evaluation of multiple sclerosis (MS). These include its essential place in the initial evaluation of patients suspected of having the disease to secure and sometimes reject the diagnosis of $\mathrm{MS},{ }^{1,2}$ as a prognostic tool at first presentation of symptoms highly suspicious of acute inflammatory CNS demyelination, ${ }^{3}$ in providing primary outcome measures in phase I/II trials, and as a source of critical supportive outcome measures in phase III trials of MS therapeutics. The utility of MRI in MS in large measure stems from its extreme sensitivity to changes in regional proton relaxation times that occur with processes that alter tissue water content and constraints on hydrogen molecule motion, particularly those associated

Address correspondence and reprint requests to Rohit Bakshi, M.D., FAAN Brigham \& Women's Hospital Harvard Medical School, 77 Avenue Louis Pasteur, HIM 730, Boston, MA 02115. E-mail: rbakshi@bwh.harvard.edu. with tissue bound and free water molecules. However, all current MRI methodology remains insensitive to the underlying disease processes that give rise to these alterations. Consequently, the specificity of altered MRI signals is limited, and overinterpretation of MRI to imply specific histopathologic tissue alterations abounds. Most patterns and distributions of lesions found on conventional and even advanced MRI are neither disease-specific nor reflect a specific histopathology. As a result, a broad differential diagnosis usually remains when MRI is viewed in isolation from the clinical history, physical and neurologic findings and laboratory investigations. Nevertheless, understanding the sequence of events that correlate with conventional MRI-visible lesion formation, and the most characteristic topography of lesions in the cerebrum, brainstem, and spinal cord help to determine the likelihood that a patient has MS and provide reasonable markers by which to infer therapeutic effects on the evolving underlying disease process.

Current conventional MRI consists of several series of image acquisitions based on generally available pulse sequences developed to provide optimal tissue contrast 
for routine clinical diagnostic work. In general, these have also been the mainstay for addressing disease activity in clinical trials. A standardized approach to imaging MS patients developed by the Consortium of MS Centers (http:// www.mscare.org/pdf/MRIProtocol2003.pdf) includes sagittal fluid attenuated inversion recovery (FLAIR), axial dual echo proton density and T2 weighted (TE1 usually $<30 \mathrm{~ms}$ and TE2 $>80 \mathrm{~ms}$ ), axial FLAIR and an axial gadolinium chelate (Gd) enhanced T1-weighted image series. The post Gd T1 series is especially important in suspected MS if suspicious lesions are seen on T2-weighted or FLAIR images. Advanced MRI including quantification of magnetization transfer ratio (MTR), dual inversion recovery imaging, diffusion tensor imaging, single voxel, two-dimensional (2D) and three-dimensional (3D) chemical shift imaging, and unlocalized spectroscopy signal from whole brain magnetic resonance spectroscopy (MRS), among other methods have enriched our understanding of conventional MRI and have added insight into our understanding of the pathogenesis of MS. ${ }^{4}$ However, these more advanced methods are not generally available, nor necessary for diagnosis and follow-up evaluations, although they may provide additional outcomes through which to determine drug efficacy.

In this article, we will review individual MRI-defined changes detected by a broad variety of conventional and advanced imaging approaches. We will emphasize their specific utility in understanding the pathogenesis of the disease and serving as biomarkers for evaluating treatment effects, including therapeutic effects on tissue preservation or repair within the otherwise relatively inaccessible CNS. To lay the groundwork for this review, it is important to first understand individual lesion development and maturation as currently viewed using conventional and advanced imaging.

\section{LESION EVOLUTION}

On conventional MRI, new lesions arising in previously normal appearing white matter (NAWM) are nearly always announced by a nodular area of Gd-enhancement on T1-weighted images (FIG. 1) ${ }^{5}$ This is nearly invariably associated with a hyperintense lesion in the same location on T2-weighted images (FIG. 1). ${ }^{6}$ Nearly $65 \%$ of the larger enhancements correspond to hypointense lesions visualized on noncontrast T1weighted images ${ }^{7}$ (FIG. 2). Most enhancements fade and disappear over 4-6 weeks, and 50\% of the hypointensities spontaneously resolve within 4 weeks. A similar proportion of those found at 1 month disappear over the next 4-5 months ${ }^{8}$ Return to the T1-isointense state or mild $\mathrm{T} 1$ hypointensity may indicate extensive or partial remyelination. ${ }^{9}$ The extent of the new T2-hyperintense lesion usually contracts and its intensity is reduced as edema resolves and some tissue repair occurs. However, most lesions, once evident on T2-weighted images rarely disappear unless they are located in the brainstem or spinal cord. Potentially more aggressive lesions show ring-like propagation of the enhancement over a few weeks or longer before the enhancement begins to fade, are associated with more complex appearances on T2weighted images, a central spherical hypointensity on T1-weighted images, and persistence over time (FIG. 3). An incomplete ring of enhancement ("open ring sign"), open where the lesion abuts gray matter, is characteristic of MS (FIG. 2). ${ }^{10}$ A complete ring may also be seen, particularly when the lesions are confined to the white matter (FIG. 3). Careful inspection of the areas surrounding some of the larger T1-hypointense lesion that contract over time shows this apparent repair to be at the expense of surrounding tissue loss. As the center of such lesions likely undergoes gliosis and contraction there is regional ventricular enlargement and cortical volume loss directed toward the lesion. Although the evolution of T1-hypointense lesions is intimately associated with enhancements, the relationship must be more complex. Enhancement frequency is age dependent, being less frequent among older (rather than younger) MS patients of all disease subtypes. ${ }^{11,12}$ Yet, hypointense lesions are more common with longer disease duration and among the progressive disease subtypes. The divergent behavior of these seemingly inter-related MRI metrics might suggest that whereas some hypointense lesions result directly from new inflammatory events that are readily monitored by enhancements on MRI, other hypointense lesions may evolve differently.

Lesion evolution is more complex when monitored with advanced imaging. Newly enhanced lesions that form within previously conventional MRI-defined NAWM provide informative regions for retrospective scrutiny for change that antedates lesion evolution on conventional MRI. Retrospective analyses suggest that regional abnormalities in MTR develop in NAWM months before the enhancement is seen by conventional MRI. ${ }^{13,14}$ Unfortunately, these changes have not been robust enough to use prospectively. Focal increases in choline and the appearance of signals on MR spectroscopic imaging (MRSI) consistent with alterations in lipids or other myelin associated macromolecules also precede lesion formation by several months, ${ }^{15,16}$ to suggest that focal disruptions of tissue integrity anticipate enhancements. It remains unclear whether these changes reflect some primary intrinsic tissue process that eventually signals a secondary influx of inflammatory cells, or whether they reflect microscopic inflammatory change beyond the resolution of conventional imaging that must first build before a cascading inflammatory response is evident. In either case, with enhancement there is a dramatic fall in regional MTR, drop in $\mathrm{N}$-acetylaspartate (NAA), increase in choline, the appearance of signals 


\section{Typical MRI Features of MS}
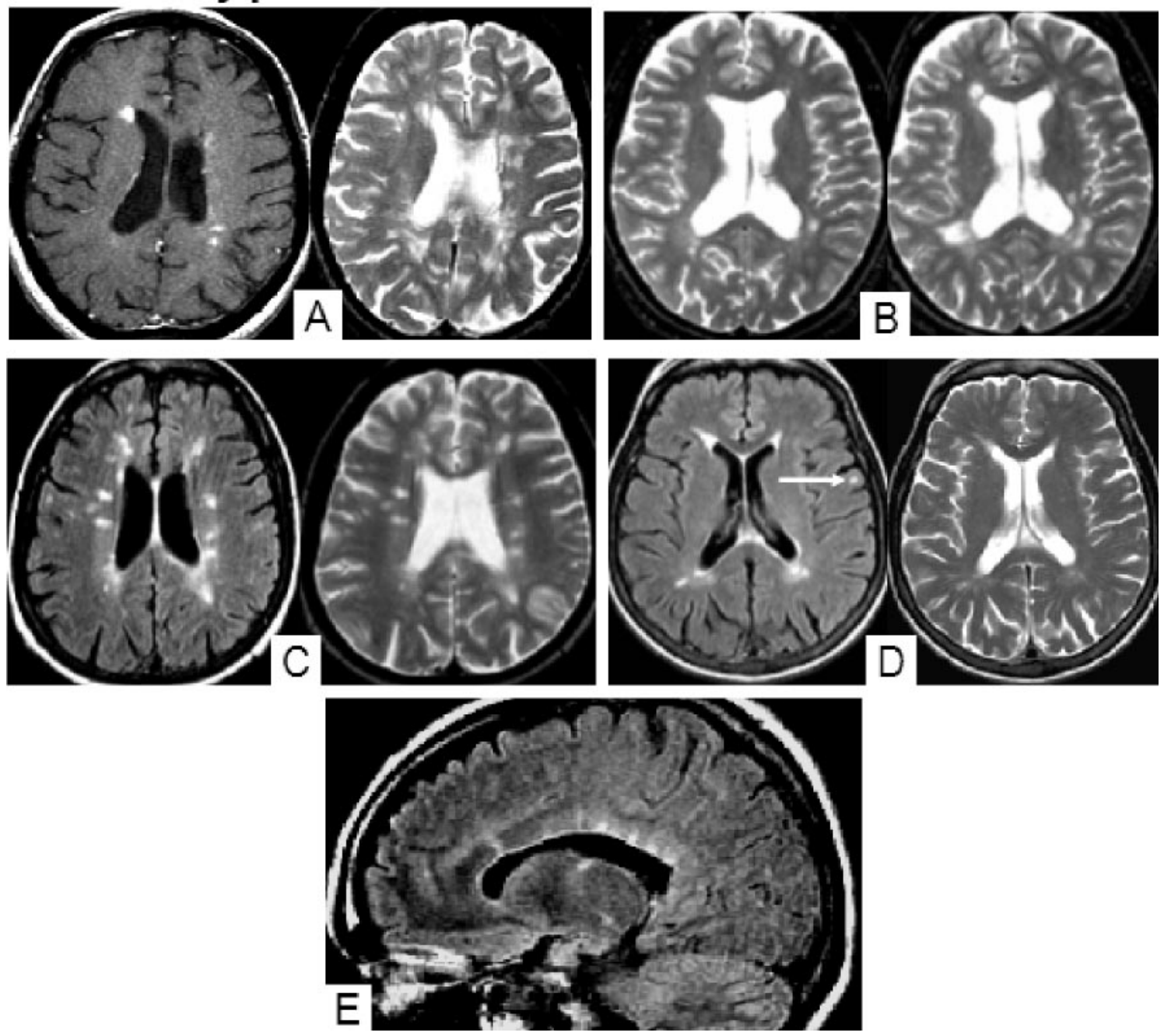

FIG. 1. Montage of five patients showing typical MRI features of MS. A: Post-contrast (left) and CSE T2-weighted (right) images are shown of a 51-year-old woman with RR MS. Note several enhancing foci in the periventricular region bilaterally. Lesions have a homogeneous appearance and show corresponding hyperintensity on the T2-weighted image. B: Baseline (left) and 5-year follow-up (right) CSE T2-weighted images of a 46-year-old woman with RR MS. EDSS score increased from 2.0 to 3.5 during this time. Note progressive number and total volume of T2-hyperintense lesions. C: FLAIR (left) and FSE T2-weighted (right) images of a 41-year-old woman with RR MS and EDSS score of 3 illustrates the superiority of FLAIR for the detection of periventricular lesions. Note the characteristic appearance of the lesions including an oval/ovoid morphology, size $5 \mathrm{~mm}$ or greater in diameter, and tendency to directly abut the ventricular margin. D: FLAIR (left) and FSE T2-weighted (right) images of a 51-year-old woman with RR MS and EDSS score of 4 shows the superiority of FLAIR for the detection of cortical/juxta-cortical lesions. Note the lesion in the left temporal lobe (arrow) seen by FLAIR but not on the T2-weighted image. E: Sagittal FLAIR of a 27-year-old woman with RR MS shows typical perivenular orientation of lesions. Note the lesions are perpendicular to the long axis of the lateral ventricles giving an appearance known as "Dawson's fingers."

from myelin breakdown products, and increases of myoinositol, glutamate + glutamine (Glx) and lactate. ${ }^{17}$ The biochemical changes are highly dynamic and the concentrations of various metabolites and MTR tend to recover toward their normal values with time. Some of the observed acute changes are in part explained by dilutional effects of acute vasogenic edema. ${ }^{18}$ MTR values do not fully normalize, but a return toward normal is accompanied by partial or complete resolution of associated T1hypointense lesions. Mildly T1-hypointense lesions that remain with intermediate MTR values correlate with histopathologic evidence of at least partial remyelination. ${ }^{9}$ Persistent T1-hypointense lesions show diminished NAA indicative of irreversible axonal $\operatorname{loss}^{19}$; they may also show increased myo-inositol, possibly indicative of gliosis. Enhanced lesions generally have increased diffusion, decreased FA, and altered diffusion tensor values, and these alterations persist to a variable extent in those lesions that have the most severely altered tissue matrix. $^{20}$ The specialized anatomy of the brain results in 


\section{Evolution of T1-hypointense Lesions}

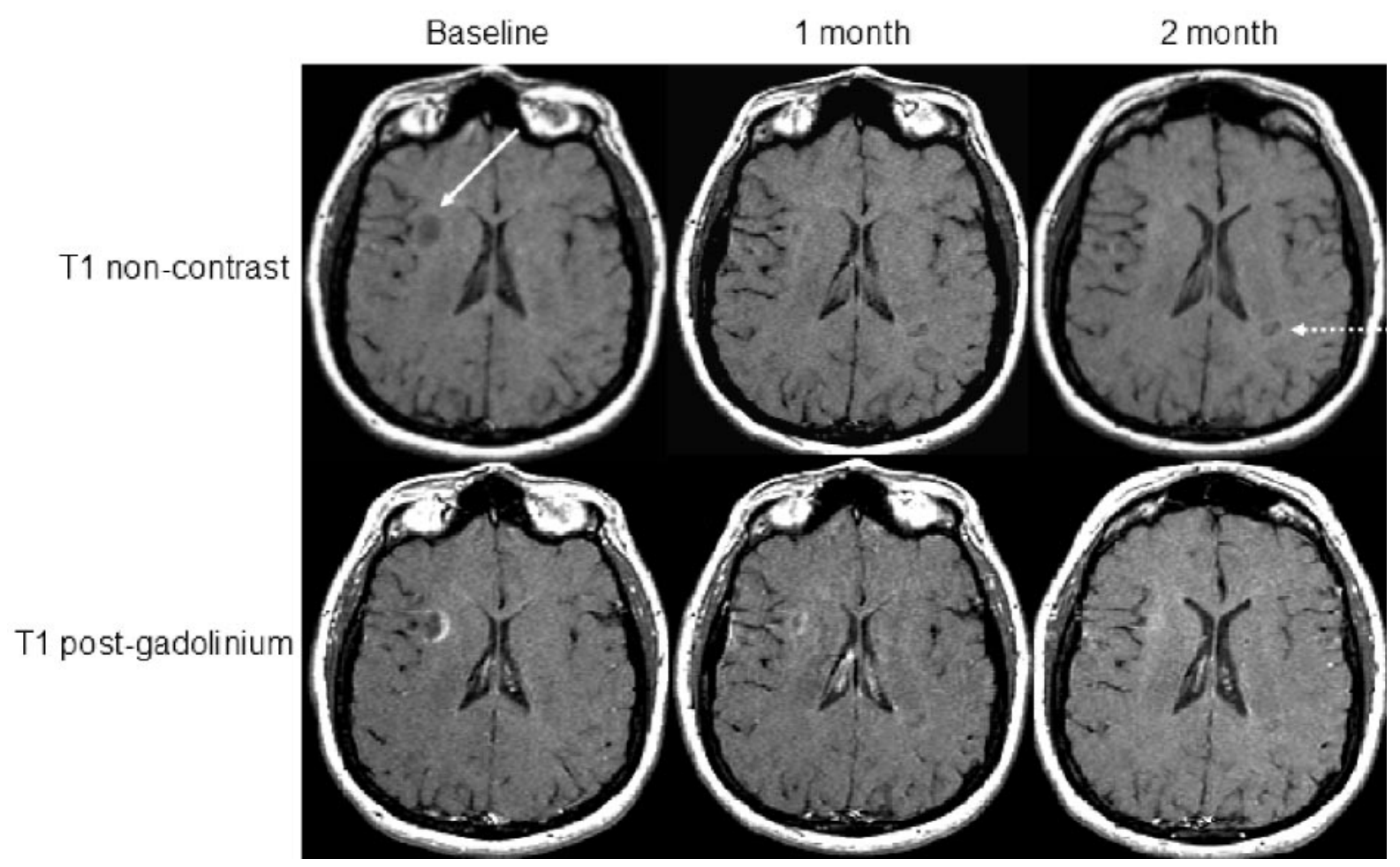

FIG. 2. Evolution of $T 1$ hypointensities ("black holes"). A 48-year-old woman with RR MS received serial MRI during the pretreatment screening period of a clinical trial. Noncontrast (upper row) and post-contrast (lower row) images are shown. Scans were obtained at baseline, 1 month, and 2 months later. Note the ring-enhancing lesion appearing at baseline that has corresponding T1 hypointensity (solid arrow). The ring enhancement has an incomplete or open ring that is typical of MS. ${ }^{10}$ The T1 hypointensity resolves 2 months later. A second T1 hypointensity develops over 2 months (broken arrow).

alterations at a distance related to disruption along connected pathways that traverse focal lesions, and Wallerian degeneration along highly organized pathways may be reflected in altered diffusion tensor eigen values. ${ }^{21}$ These distributed effects may help to explain some of the quantitative change that is rather consistently found in conventional MRI-defined NAWM.

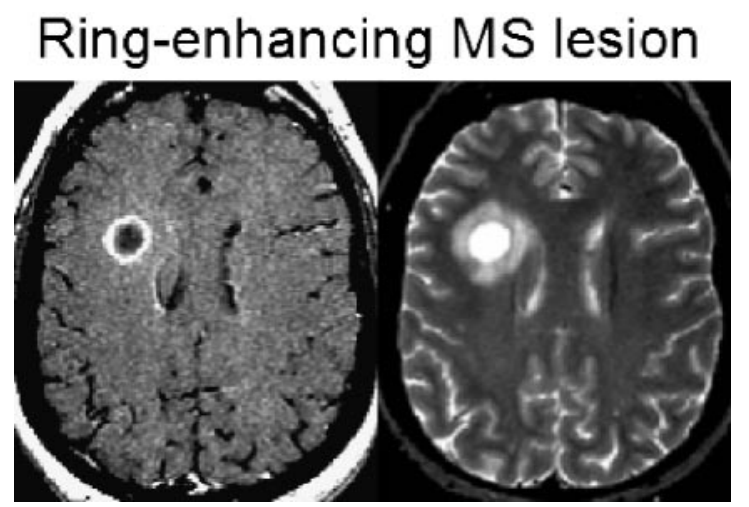

FIG. 3. T1-weighted post contrast (left) and CSE T2-weighted (right) images of a 48-year-old woman with RR MS show a ring enhancing lesion and corresponding complex appearance on the T2 image.
MRSI defines dynamic metabolite changes compatible with alterations in mobile lipids in cortical gray matter. ${ }^{22}$ These observations are consistent with the known occurrence of cortical plaques. ${ }^{23}$ However, intracortical and subpial lesions have yet to be adequately resolved by conventional MRI at up to 3 Tesla, or with other available advanced methods. Recently, postmortem MRI at 8 Tesla has identified some purely intracortical lesions (K. Rammohan, personal communication).

With this overview of lesion development and evolution as defined by MRI, we can turn to a consideration of the various conventional and advanced imaging approaches applied to MS, with particular attention to their current use or potential use in the assessment of MS disease modifying therapeutics.

\section{Hyperintense lesions on T2-weighted images}

Technical aspects. The intensity of tissue signals is influenced by proton density and the rate at which nuclear MR signals decay in the static magnetic field of the scanner following application of a radio-frequency excitation pulse as characterized by T1 (longitudinal relaxation time) and T2 (transverse relaxation time). These three parameters (proton density, $\mathrm{T} 1$, and $\mathrm{T} 2$ relaxation 
times) determine the MRI appearance; their relative influences are affected by scanning parameter changes. Proton density and T2-weighted images are generated with long repetition time (TR). At relatively short echo time (TE), the image appearance is mainly determined by proton density, whereas at relatively long TE, the T2 effect is increased. FLAIR uses an inversion pulse followed by a variable signal recovery time to maximize the contrast between tissues with different T1 values. Most clinically used FLAIR inversion pulses are designed to null the signal from CSF at a long TE to provide a high degree of T2 weighting to increase lesion conspicuity, particularly for those lesions that abut CSF pathways.

Neuropathology. The lesions of MS show considerable histopathologic heterogeneity, in part related to evolution of individual lesions over time and (possibly) to fundamental differences in patient-specific pathogenesis of lesions. ${ }^{24}$ However, with the possible exception of large ring-enhanced lesions, lesion appearance and patterns seen by conventional MRI have thus far failed to consistently distinguish among these histopathologic subtypes. The extent of MRI-defined T2 hyperintense lesions seen on postmortem imaging clearly can approximate the extent of lesions found on direct histopathologic tissue examination. ${ }^{25,26}$ Postmortem MRI allows for the detection of regions of microscopic inflammation or active demyelination otherwise missed by visual inspection of the tissue. ${ }^{27,28}$ Moreover, there are considerable MRI-defined lesion abnormalities that exceed the sensitivity of histopathologically defined plaque burden. ${ }^{29}$ These discrepancies are readily explained by the basis of the signal generated by T2-weighted image as described above, which is highly sensitive to the tissue mobility of protons, but influenced to a lesser extent by the underlying processes that give rise to altered tissue water content and proton mobility. Thus, hyperintensities on T2-weighted images in patients with MS are nonspecific for the relative degree of underlying inflammation, edema, demyelination, axonal damage, Wallerian degeneration, and gliosis.

Clinical correlation. Both cross-sectional and shortterm longitudinal correlations between T2-hyperintense disease burden (T2 BOD) and clinical impairment are generally poor. ${ }^{30-32}$ The possible reasons for this are numerous and readily attributed to the lack of pathologic specificity for the extent of tissue destruction and the well known limitations of existent clinical rating systems, including the benchmark Expanded Disability Status Scale (EDSS). ${ }^{32}$ One of the main reasons for the lack of correlation is that MRI often shows hemispheric involvement in areas that are clinically silent. However, the biologic burden of the disease is probably reflected better by the MRI findings. Despite these limitations, more focused attention may provide some hope that better correlations may be possible if restricted over appro- priate phases of the disease. T2 BOD is quite variable among patients when evaluated at the earliest clinically recognized stage of the disease, with a clinically isolated demyelinating syndrome (CIS) highly suggestive of the type seen in relapsing-remitting (RR) MS patients. Even so, it is at this stage that differences in T2 BOD have strong predictive value for distinguishing the subsequent short-term clinical course. The best available data suggest that about a third of patients presenting with CIS will have negative cerebral MRI and about $40 \%$ will have fewer than two lesions. In the Early Treatment of Multiple Sclerosis (ETOMS) study of CIS, ${ }^{33}$ independent of treatment, conversion to clinical definite MS (CDMS) occurred in $41 \%$ of patients with at least one Gd-enhancing lesion or 9 T2-hyperintense lesions, versus $11 \%$ of those without either. The best data on follow-up at 5 or more years after presentation come from subjects gathered nearly two decades ago. ${ }^{34}$ A number of reports have concentrated on similar patients followed for shorter intervals. CIS patients with normal cerebral MRI at presentation have only a 5\% risk of another clinical attack (progressing to CDMS) in the next 1-5 years; those with cerebral lesions have a considerably higher risk. The risk remains below 50\% until the cerebral T2 BOD exceeds $1.2 \mathrm{ml}$; corresponding to about six lesions each of about $5 \mathrm{~mm}$ in diameter at $5-\mathrm{mm}$ slice thickness. ${ }^{35}$ The risk of progression to CDMS within 10 years with a negative MRI at presentation remained low at $11 \%$, but 2 or more lesions conferred nearly a $90 \%$ risk of conversion. ${ }^{36}$ Of those with an abnormal MRI scan, $31 \%$ developed disability equivalent to an EDSS score of at least 6.0 within 14 years, and the EDSS score at 14 years correlated moderately with the increase in lesion volume in the initial first 5 years $(\mathrm{r}=0.61)$.

International panel MRI criteria for dissemination in time require one or more new Gd-enhanced lesions at least 3 months after the initial clinical event or a new T2-hyperintense lesion identified at least 3 months after a baseline set of images obtained after the presenting clinical event had stabilized or resolved. ${ }^{1}$ Admittedly, these time intervals are somewhat arbitrary. They were originally developed because most new Gd-enhanced lesions will no longer enhance after $6-8$ weeks, and that new lesions continue to appear for some days to weeks in association with a single clinical attack. ${ }^{37}$ Subsequent data have generally supported the utility of follow-up MRI at 3 months to refine the predictive value of early MRI for conversion to CDMS..$^{38,39}$

Two clinical trials of different preparations of interferon $\beta$ (IFNB)-1a indirectly address the sensitivity of the international panel MRI criteria for dissemination in space in the early diagnosis of MS. The Controlled High Risk Avonex Multiple Sclerosis trial studied patients with monosymptomatic CIS. ${ }^{40}$ Entry criteria were restricted to subjects with at least two clinically silent 
cerebral lesions of $\geq 3 \mathrm{~mm}$ diameter on a screening MRI scan, one of which needed to be periventricular or ovoid. Only $1-3 \%$ of all subjects met the minimum number of T2-hyperintense lesions, and $70 \%$ of all patients had $\geq 9$ lesions at baseline. ${ }^{41}$ It is not known what proportion of these subjects would have met the international panel MRI criteria for dissemination in space, but this likely exceeded $70 \%$ of the entire cohort. Within 6 months of follow up, about half of those patients without a second clinical attack met international panel MRI criteria for dissemination in time for MS, and two-thirds of those without an attack by 18 months fulfilled the panel criteria for MS, regardless of treatment assignment. The ETOMS study enrolled patients with either monosymptomatic or polysymptomatic CIS. ${ }^{33}$ They required patients to have at least four cerebral lesions at entry (three sufficed if at least one was infratentorial or Gd-enhanced). Only $11 \%$ of these subjects were free of MRI activity on biannual scans over 2 years, regardless of treatment assignment. Thus, regardless of whether treatment is initiated at clinical presentation in subjects with CIS who have at least two to three cerebral lesions, imaging to define dissemination in time by international panel guidelines will more rapidly establish a firm diagnosis of MS than will clinical criteria. Whether some MRI patterns in isolation are adequate for a diagnosis of MS at or before first clinical presentation remains unclear. Similarly, the optimal timing and cost effective number of serial MRI scans needed to define dissemination in time for patients with CIS are not established.

Role in therapeutic monitoring. Historically, T2 BOD was first used as potential supportive outcome in major clinical trials of cyclosporine versus azathioprine in Europe, and versus placebo in North America. ${ }^{42-45}$ Both studies failed to show clinical benefit, and both documented progression of MRI-monitored pathology that was unaffected by treatment. Several years later, the first study used attenuated change in T2 BOD on active treatment with IFNB-1b compared with placebo to supplement the clinical endpoint and support drug approval by the FDA. ${ }^{46}$ In that study, subjective but blinded assessment of MRI-defined disease showed that the number of scans deemed active by the appearance of new T2-hyperintense lesions was significantly reduced by active therapy. Moreover, a quantitative measure of the area of T2-hyperintense lesions was also reduced $23 \%$ by treatment compared with placebo.

The T2-based measures that have evolved to monitor treatment are both qualitative and quantitative. An active scan designates that one or more new T2-hyperintense lesions have appeared as compared with the prior scan, and/or previously noted lesions have enlarged (i.e., enlarged by $\sim 20 \%$ in lesional area in a single slice). The number of new and/or enlarging T2-hyperintense lesions can also be enumerated. These measures are based on
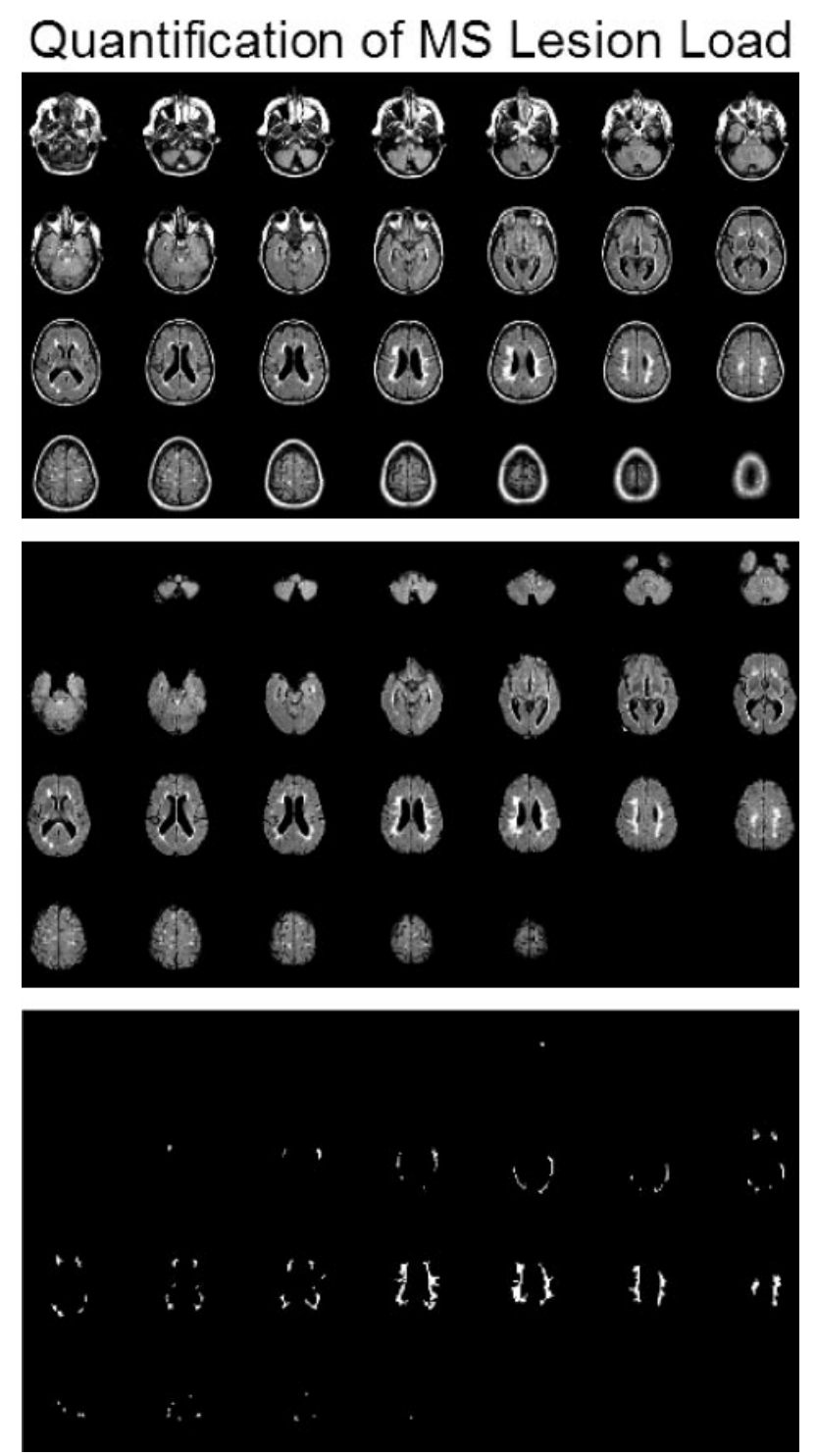

FIG. 4. A quantitative computer-assisted semiautomated meth$\operatorname{od}^{170}$ of determining total brain T2 hyperintense lesion load illustrated in a patient with MS. Upper panel: raw FLAIR images; middle panel: after masking and nulling of skull, other extracranial tissue, and CSF flow artifacts; lower panel: after thresholding, the images are segmented into lesion versus nonlesion tissue; the area and volume of total brain lesions is determined based on the number of voxels retained.

subjective assessment of serially obtained images and generally require that the images are obtained and displayed in standardized manner. Each image analysis center usually develops its own set of standards on how to interpret the suitability of the images for analysis, and for defining a new or enlarging lesion. Estimating the T2 BOD has been performed by manual tracing of lesion boundaries, semiautomated thresholding techniques like seed growing and contouring (FIG. 4), and more fully automated image analysis based on a number of approaches. The constraints imposed by the techniques on image acquisition and variations in reproducibility vary 
TABLE 1. T2 Activity in Placebo Groups from Selected Controlled Trials

\begin{tabular}{|c|c|c|c|c|c|c|c|c|c|c|c|}
\hline \multirow[b]{2}{*}{ Study } & \multirow[b]{2}{*}{ Course } & \multicolumn{6}{|c|}{$\begin{array}{l}\text { Median Percent Change T2 BOD from } \\
\text { Baseline by Interval in Months }\end{array}$} & \multirow{2}{*}{$\begin{array}{l}\text { New T2- } \\
\text { Hyperintense } \\
\text { Lesions }\end{array}$} & \multirow{2}{*}{$\begin{array}{l}\text { No T2 } \\
\text { Activity }\end{array}$} & \multirow{2}{*}{$\begin{array}{l}\text { T2 } \\
\text { Active }\end{array}$} & \multirow[b]{2}{*}{ Reference } \\
\hline & & 6 & 9 & 12 & 18 & 24 & 36 & & & & \\
\hline IFNB-1a & $\mathrm{RR}$ & 4 & & 6.4 & 10.8 & 10.9 & & 2.25 & $8 \%$ & $75 \%$ & 48 \\
\hline IFNB-1b & $\mathrm{RR}$ & & & 10.9 & & 16.5 & 15 & & & & 46 \\
\hline IFNB-1a & SP & $1 *$ & & $1.8^{*}$ & $3.5^{*}$ & $6.2^{*}$ & 10 & $4.67 *$ & $24 \%$ & $50 \%$ & 49 \\
\hline IFNB-1b & SP & & & 1.6 & & 2.4 & 11 & 5.0 & $16 \%$ & $84 \%$ & 50 \\
\hline GA & $\mathrm{RR}$ & & 26 & & & & & 8.0 & & & 51 \\
\hline IFNB-1a & CIS & & & & & 8.8 & & $6.0^{*}$ & $16 \%$ & & 33 \\
\hline
\end{tabular}

*Estimated from data provided in original article; exact metric not in article. Trial duration is indicated by shading of the cells for each trial.

with the methods and among imaging analysis centers. Nonetheless, these estimates show sensitivity to change over time and for detecting treatment effects. ${ }^{47-51}$

As seen in Table 1, the longitudinal changes on various measures of T2-hyperintense lesions in placebo-assigned subjects have varied among studies. Some of these differences can be attributed to patient characteristics with activity levels over a given time interval seemingly higher in the earlier stages of the disease than in cohorts selected for secondary progressive (SP) disease at entry, by enrichment for subjects with active MRI scans at entry into short-term trials, and by improvements in imaging protocols over time. In all instances listed in Table 1, positive effects of treatment on clinical endpoints were accompanied by statistically significant effects on T2-hyperintense lesions. Most of these studies chose sample sizes not based on estimates of the MRI effect size, but rather on anticipated effects of the drug on the selected clinical outcome variable.

Molyneux and colleagues ${ }^{52}$ used data aggregated on 128 subjects with RR or SP MS from natural history data or placebo arms of several studies. The database only provided actual observations for 12 months of follow-up, but sample size estimates were constructed for studies of up to 3 years' duration on the assumption that increase in T2 BOD would remain linear over time. As illustrated in Table 1, this assumption does not hold for actual trial cohorts. Nevertheless, they projected that if a drug were completely effective in containing further increase in T2 BOD from trial entry, 60 RR MS subjects per arm would be needed for a 1-year study and only 12 RRMS subjects per arm would be needed for 3 years to have $80 \%$ power for a treatment effect. Numbers of subjects needed to show a $50 \%$ reduction in $\mathrm{T} 2 \mathrm{BOD}$ progression were estimated at 232 for a 1-year trial and 38 for a 3-year trial. If the study were of SP MS, the numbers of subjects increased by two- to threefold, reflecting the slower accumulation of T2 BOD in more progressive subjects. ${ }^{52}$ More precise estimates might be derived from larger integrated data sets, such those being acquired by the Sylvia Lawry Center for MS Research, an international collabora- tive database containing natural history data from numerous clinical studies (http://www.slcmsr.com/).

\section{Gadolinium-enhanced lesions}

Technical aspects. Paramagnetic contrast agents markedly shorten the $\mathrm{T} 1$ of neighboring water protons. As a result, after intravenous bolus administration, they locally increase the signal from brain tissue where there is normally no blood brain barrier (e.g., the circumventricular organs, meninges, and choroid plexus), or where the barrier is significantly compromised allowing $\mathrm{Gd}$ to enter the brain abnormally, e.g., in active MS lesions (FIGS. 1-3). This effect is best monitored on T1weighted images and the conspicuity of enhancement can be improved by inclusion of an off resonance magnetization transfer (MT) pulse. ${ }^{53}$ Protons from water molecules that are tightly bound to tissue contribute little signal to images acquired with conventional MRI. When a narrow bandwidth radio-frequency pulse with a 1-2 $\mathrm{KHz}$ frequency offset from the excitation pulse is used to saturate protons associated with the bound water pool, magnetization is transferred from the bound to free water pool that contributes the most signal to conventional MRI. The result is attenuation of the signal proportional to the concentration of the bound water molecules, providing an estimate of tissue integrity. The MT pulse does not directly affect the free water signal. In the case where the pulse is applied to post Gd-T1 imaging, the signal from brain tissue is reduced and the Gd effect is augmented by comparison. ${ }^{53}$ The extent and number of enhancements found may be increased by the dose of contrast selected or by an optimal delay between contrast administration and the time to image acquisition. ${ }^{53,54}$

Neuropathology. The pathologic correlate of enhancement in MS is altered blood brain barrier permeability in the setting of acute perivascular inflammation. ${ }^{55-57}$ Transfer of Gd into the CNS is likely complex, reflecting components of transendothelial transfer by increased micropinocytotic activity of activated but structurally intact endothelium and passive entry through structurally damaged endothelial barriers. 
TABLE 2. Enhancement Activity and Clinical Effects from Selected Controlled Trials

\begin{tabular}{|c|c|c|c|c|}
\hline Study & Course & Effect on Enhancement & Clinical Effect & Reference \\
\hline IFNB-1a & $\mathrm{RR}$ & $\begin{array}{l}\text { Median new and recurrent en- } \\
\text { hancements over first } 9 \text { months } \\
\text { on therapy reduced from } 8.0 \text { to } \\
1.4(22 \mu \mathrm{g}) \text { and } 1.3(44 \mu \mathrm{g})\end{array}$ & $\begin{array}{l}\text { Relapse risk reduction } 27 \%(22 \\
\mu \mathrm{g}) \text { and } 33 \%(44 \mu \mathrm{g}) \text { at } 2 \\
\text { years }\end{array}$ & 48,62 \\
\hline GA & $\mathrm{RR}$ & $\begin{array}{l}\text { Median new enhancements over } 9 \\
\text { months on therapy reduced } \\
\text { from } 13.5 \text { to } 9.0\end{array}$ & $\begin{array}{l}\text { Annualized relapse rate reduced } \\
\text { from } 1.21 \text { to } 0.81 \text { over } 9 \\
\text { months }\end{array}$ & 51 \\
\hline Natalizumab & $\mathrm{RR}$ & $\begin{array}{l}\text { Median new enhancements over } 6 \\
\text { months on therapy reduced } \\
\text { from } 2.0 \text { to } 0(3 \mathrm{mg} / \mathrm{kg}) \text { and } 0 \\
(6 \mathrm{mg} / \mathrm{kg})\end{array}$ & $\begin{array}{l}\text { Proportion with relapses over } 6 \\
\text { months on therapy reduced } \\
\text { from } 38 \% \text { to } 19 \%(3 \mathrm{mg} / \mathrm{kg}) \\
\text { and } 19 \%(6 \mathrm{mg} / \mathrm{kg})\end{array}$ & 63 \\
\hline IFNB-1b & SP & $\begin{array}{l}\text { Median new enhancements over } \\
\text { first } 6 \text { months on therapy re- } \\
\text { duced from } 5.0 \text { to } 0\end{array}$ & $\begin{array}{l}\text { Odds ratio for confirmed progres- } \\
\text { sion over } 2-3 \text { years was } 0.65\end{array}$ & 50,64 \\
\hline Cladribine & SP \& PP & $\begin{array}{l}\text { Proportions with enhanced scans } \\
\text { at } 6 \text { and } 12 \text { months reduced } \\
\text { from } 33 \text { and } 32 \% \text {, to } 12 \text { and } \\
2 \%(0.7 \mathrm{mg} / \mathrm{kg}) \text {, and } 2 \text { to } 6 \% \\
(2.1 \mathrm{mg} / \mathrm{kg}) \text {, respectively }\end{array}$ & $\begin{array}{l}\text { No change in time to progression } \\
\text { by EDSS }\end{array}$ & 65 \\
\hline
\end{tabular}

Clinical correlation. In clinically eloquent regions, new clinical symptoms are highly correlated with the appearance and resolution of enhancement in that pathway. In one study, 94\% of 107 patients with acute optic neuritis showed enhancement of the affected optic nerve. ${ }^{58}$ Altered blood brain barrier permeability is common in acute optic neuritis, frequently associated with abnormal visual acuity and visual evoked potentials, and generally disappears as vision improves. ${ }^{59}$ However, most enhanced activity on serial scanning occurs in the absence of clinical symptoms. ${ }^{60}$ As a consequence, subclinical disease activity as reflected by various measures of Gd enhancement (presence of one or more enhancements defining an active scan, total number of distinct enhancements, or total volume of enhanced tissue) greatly exceeds clinical measures of activity. A metaanalysis of enhancement frequency occurring over 6 months of serial monthly imaging showed predictive value for the number of clinical relapses that occurred over the next 1 and 2 years, ${ }^{61}$ but the risk ratios were modest (1.2 and 1.6). The mean number of enhancements seen over this interval provided a weak predictor for change in physical disability (EDSS score) over the next 1 and 2 years (odds ratios 1.3 and 1.7). Whereas the enhancement findings on a single scan had no clinical predictive value, the number of enhanced lesions on an initial scan correlated highly with subsequent enhanced lesion counts, a correlation that diminished with time.

Role in therapeutic monitoring. The close association of enhancements with acute inflammatory activity makes this an attractive MRI measure to test the effectiveness of a therapeutic agent on new inflammatory disease. However, the weak correlation of enhancements with clinical activity, whether monitored as relapses or accumulated neurological disability, render it a poor predictor of the clinical benefits that can be anticipated from the agent's use in any particular MS patient population. Thus far, all clinically useful disease modifying agents developed for MS have some measurable effect on Gd enhancement activity, but not all drugs with an effect on Gd enhancements have shown clinical benefits (Table 2). ${ }^{48,50,51,62-65}$ The apparent MRI-clinical uncoupling is, at least in part, related to defects in trial design. It is possible that drugs could have a beneficial effect on clinical disease without an effect on enhancement, but this appears unlikely for any anti-inflammatory agents.

Trial designs based on enhancements as a primary outcome are designed to determine if a drug has enough potential to proceed to a definitive trial with clinical endpoints. These trials have focused on sample sizes needed for a positive treatment effect on Gd-enhancing lesions of a particular magnitude. These simulations have been based on reasonably sized aggregated natural history and trial placebo cohorts, and generally assume that the drug effect sought has a rapid onset. Because enhancements in any study population are not normally distributed, nonparametric analyses are generally assumed. The size of the sample needed is usually found to be smallest when the number Gd-enhancing lesions is the primary measure, somewhat larger for the binary outcome of whether a scan contains enhancements, ${ }^{66}$ and largest when based on enhanced tissue volume due to the greater variance associated with this measure. Using new enhancement numbers, a $70 \%$ treatment effect can be expected with excellent power using about 50 subjects per cohort in a parallel design trial within 3 months of 
serial monthly imaging ${ }^{66}$; indeed, the numbers are likely to be smaller if variance drops in the treated group as should be expected. More recently, it was proposed that a negative binomial better describes the variability of enhancement numbers seen in MS cohorts than a Poisson distribution, allowing simpler analytic approaches to the data. ${ }^{67}$ In modeling sample size, it is important to consider the anticipated baseline enhancement frequency anticipated in the patients to be entered into the trial. In general, younger patients and those with relatively recent clinical relapses will provide more enhancement activity at baseline than older subjects who have SP or particularly primary progressive (PP) MS with distant or no prior clinical attacks. Similarly, enriching the study sample for enhancement activity on a baseline scan will reduce sample size requirements. In considering studies of combined therapy, or a new drug tested against an established effective agent, the time course and magnitude of the effect of the established agent will greatly inflate the number of subjects needed to demonstrate an additive effect of the new agent. ${ }^{68}$

Sample size considerations must also be adjusted if the MRI techniques differ substantially from the "standard." Doses of Gd greater than $0.1 \mathrm{mmol} / \mathrm{kg}$, the application of MT pulses, significant delays from injection to image acquisition, or increased scan frequency may result in higher yields of Gd-enhanced outcome measures. ${ }^{53,54,69}$ While the use of these procedures can be sample size sparing in exploratory proof of principal trials, the apparent effect size of the therapy can differ depending upon the method used and the drug in question. ${ }^{70,71}$ As a result, projections of what may be seen in a phase III trial that may use more conventional enhancement methods may not follow directly from the pilot study results.

Increasing emphasis has been placed on the use of Gd-enhanced MRI as a potential safety biomarker rather than as an efficacy biomarker, with few published data to support this claim. However, phase I/II studies that enrich for baseline-enhancing activity to improve power for efficacy will likely degrade the ability to detect adverse effects of the drug on the disease. Selecting subjects for low entry enhancing activity will correspondingly improve the ability of MRI as a marker of adverse effects on the disease or in combination trials where enhanced MRI can serve as a sensitive indicator of adverse pharmacodynamic interactions of the new combination with an established agent. There are examples of failure of MRI to predict drug-associated increase in relapses, ${ }^{72}$ or drug-induced disease activation. ${ }^{73}$

\section{Hypointense lesions on T1-weighted images}

Technical aspects. A subset of MS plaques seen on T2-weighted images may appear hypointense on corresponding T1-weighted images when compared to the surrounding NAWM of the T1-weighted image (FIG.
2). ${ }^{74}$ These T1-hypointense regions ("black holes") may correspond to all or only a portion of the T2-hyperintense plaque. The extent of T1 hypointensity is dependent upon the MRI pulse sequence, whether the noncontrast or post-Gd T1-images are considered, and whether an offresonance MT pulse is applied. ${ }^{11}$ This may account for differences in the results reported among image analysis centers. There is a relatively strong correlation between the hypointense component found on FLAIR-based T2 images and the T1-hypointense lesion burden. ${ }^{75}$

Neuropathology. The pathological correlates of T1hypointense lesions are dependent, in part, on the lesion age. Recently formed T1-hypointense lesions likely reflect variable combinations of inflammation, edema, demyelination, early remyelination, axonal transection, and glial (microglial/astrocyte) activation. Those acute T1hypointense lesions associated with smaller amounts of tissue enhancement and with shorter durations of tissue enhancement on serial scans have a higher probability of reverting to isointense regions (FIG. 2). ${ }^{7,76}$ This likely reflects resolution of edema and at least partial remyelination of affected tissue., ${ }^{9,77}$ Approximately half of newly formed T1-hypointense lesions will disappear during the natural course of the disease ${ }^{7}$; those that disappear generally will do so within 6 months. ${ }^{8}$ However, a significant proportion of the larger lesions that disappear or decrease in size later than 6 months may do so at the expense of gliosis and atrophy. ${ }^{77-80}$ The potential reversible nature of the pathologic process associated with T1-hypointense lesions is supported by correlation with serial spectroscopic assessments in which recovery of axonal integrity [N-acetyl aspartate (NAA)] suggests transient dilutional effects of edema and metabolic dysfunction of axons in recovering black holes ${ }^{15}$ or permanent reduction in NAA correlated with sustained black holes and accumulating clinical disability. ${ }^{81,82}$ Certainly, those lesions that show the most profound hypointensity on T1-weighted post mortem images correlate pathologically with the most profound demyelination and axonal loss. ${ }^{9,19,79,80}$ In a cross-sectional study of black holes, diminished concentrations of NAA were found in nearly all lesions studied. However, the presence of increased levels of choline suggested ongoing lesional activity in the absence of detected enhancement. ${ }^{83}$

Clinical correlation. The early descriptions of black holes suggested a strong clinical correlation between T1-hypointense disease burden and clinical disability as measured by the EDSS, particularly in patients with SP MS. ${ }^{84}$ Whereas subsequent series have shown weaker correlations, the total T1-hypointense lesion volume and its change over time remain the conventional MRI lesion measures that are most strongly associated with neurologic impairment. The propensity for T2-hyperintense lesions to develop T1 hypointensity may be, in part, genetically determined. In one natural history study, sub- 
jects carrying the apolipoprotein E- $\epsilon 4$ allele were much more likely to increase their proportionate T1-hypointense lesion load than those who lacked the allele. ${ }^{85}$ T1-hypointense lesion load as a proportion of the T2hyperintense lesion load is higher in patients with progressive disease compared with those with RR disease. ${ }^{86}$ Complicating the interpretation of bulk T1-hypointense lesion load in either cross-sectional or longitudinal analyses is the potential for the simultaneous occurrence of resolution and evolution of lesions. This can be addressed by following newly occurring individual lesions, ${ }^{8}$ but this is more labor intensive.

Role in therapeutic monitoring. Several investigators have used the longitudinal change in T1-hypointense lesion volume as an exploratory outcome measure in therapeutic trials. Measurable drug-associated reductions in the accumulation of new T1-hypointense lesion volumes have been seen as early as 3 months into therapy. ${ }^{11}$ Moreover, when studied, most immunomodulatory agents have shown modest effects on attenuating T1hypointense volume increases in RR patient cohorts. ${ }^{8,87-89}$ In SP MS, T1-hypointense volume accumulation may be less dependent on new enhancement activity. ${ }^{90}$ In a subcohort representing approximately $13 \%$ of all subjects who participated in the European Study Group trial of SP MS, a linear increase over 3 years from baseline of a median of $41.8 \%$ was reported in the placebo group that was reduced to an overall median increase of $23.2 \%$ for those on IFNB-1b. ${ }^{91}$ However, in another progressive MS population treated with cladribine, a drug with a substantial effect on new enhancement formation, no clear effect was found in limiting T1-hypointense lesion evolution. ${ }^{92}$ Similarly, in a cross-over design trial an increase in T1-hypointense lesion volume occurred after enhancement activity was contained by treatment with alemtuzumab; this was correlated with the concomitant development of brain atrophy. ${ }^{93}$ Enhancements that formed despite treatment with glatiramer acetate (GA) were less likely to persist over time as T1-hypointense lesions, as compared to placebotreated patients. ${ }^{8}$ In a recent trial, ${ }^{94}$ enhancements that developed despite therapy with natalizumab were much less likely to be found $6-11$ months later, often in the absence of continued drug exposure (odds ratio 0.48 [CI $0.24-0.94]$ ). In the case of GA, this may be due to improved lesion resolution. In the case of natalizumab, reduced tissue destruction at the time of lesion formation seems the more probable explanation.

\section{MR spectroscopy}

Technical aspects. MRS can be performed using a variety of nuclei; most commonly ${ }^{1} \mathrm{H}$ and ${ }^{31} \mathrm{P}$. For a number of reasons that include sensitivity and resolution, proton MRS is most often used in MS. Whereas any mobile proton can contribute signal to MRI, the abun- dance of water in tissue overrides that of signals from protons associated with neurochemicals and macromolecules of biologic significance. ${ }^{95}$ MRS is able to sample some of these signals through suppression of water. Methods are available to capture anatomically correlated data using single voxel and 2D and 3D multivoxel procedures, or as an unlocalized signal from whole brain. ${ }^{17}$ Not all neurochemicals are detected with MRS. Myelin is highly compacted with tightly bound protons having restricted mobility such that their signals cannot be readily detected. Relatively sharp peaks are generally observed from small molecules. The most prominent proton MRSvisible compounds in normal brain include NAA (more precisely NAA, $\mathrm{N}$-aspartyl glutamate and other $\mathrm{N}$-acetyl moieties), creatine and phosphocreatine $(\mathrm{Cr})$, and choline (Cho); less prominent resonances arise from myo-inositol, glutamate, glutamine and $\gamma$-amino-butyric acid (GABA). In the presence of pathology, lactate and peaks centered between 0.9-2.1 parts per million (ppm) in the spectra that represent myelin breakdown products (mobile lipids with contributions from macromolecules derived from the catabolism of myelin proteins) may be found. Proton MRS can be performed at long or short echo times that provide different access to these molecules. MRS is quantitative, making it attractive as a potential biomarker. The differential resolution of MRS and MRI complicate partial volume calculations of metabolite concentration assignments to different normal and pathologically affected tissue types.

MRS MRI correlations. Regional increases in Cho and mobile lipids may precede conventional T2weighted MRI-based lesion detection by several months. ${ }^{15,16}$ This suggests that MRS may be more sensitive than MRI in defining microscopic regions of perivenular inflammatory demyelination, or that locally abnormal cellular metabolism or tissue integrity mark regions for a secondary inflammatory insult. Recently formed enhancing lesions in previously MRI NAWM usually show highly dynamic metabolite changes that include increased Cho and myelin breakdown products, ${ }^{96,97}$ increased myo-inositol and glutamate plus glutamine in larger ring-enhanced lesions, ${ }^{98}$ lactate and diminished NAA. ${ }^{99}$ Some early changes in metabolite levels are in part dilutional effects of acute lesional vasogenic edema. ${ }^{98}$ The decrease of NAA in acute lesions can be reversible over several weeks to months, ${ }^{15}$ possibly related to a complex interplay of resolution of local edema, return in axonal caliber and metabolite content with remyelination, and reversal of possible mitochondrial metabolic disturbances within axons traversing the active lesion. Other metabolite changes are typically transient and return to near normal values in more chronic lesions. Mobile lipid macromolecule signals rarely persist beyond 4-6 months after their appearance. Chronically persistent MRI-defined lesions lacking 
enhancement infrequently show dynamic metabolic alterations by serial MRS. Diminished NAA levels are particularly common in lesions with significant T1 hypointensiy. ${ }^{81,100}$ In persistently T1-hypointense lesions, reduced NAA indicates irreversible axonal loss. ${ }^{101}$ These permanent T1-hypointense lesions may have increased concentrations of myo-inositol, possibly as an indication of gliosis. ${ }^{100,102}$

More global reductions of NAA occur in MRI-defined NAWM adjacent to visible plaques, ${ }^{103,104}$ in larger white matter expanses with limited MRI-visible lesions, ${ }^{15,105}$ and in whole MS brain. ${ }^{106}$ These changes in NAWM are not as profound early in the disease ${ }^{107}$ as they are late in progressive cases. ${ }^{108}$ Reduction of NAA within large white matter expanses are better correlated with the entire cerebral plaque burden than the plaque burden within the region probed. This is likely the result of widespread Wallerian degeneration, if not some component of primary neurodegeneration that occurs in MS. Reduced NAA correlates with the extent of histopathologic axonal loss. ${ }^{99,109}$

Anatomically, myelin begins to envelop axons close to the neuronal cell body where it is a potential target of the disease process in MS. Purely intracortical and subpial plaques are well documented pathologically ${ }^{23,110}$ and are rarely found by conventional MRI. ${ }^{10,111}$ Their detection is improved by FLAIR MRI. ${ }^{111}$ The partial volume averaging of both CSF and white matter complicates MRS studies of cortical gray matter, necessitating careful image segmentation to minimize the problem. A serial MRSI study of patients with RR MS and minimal clinical disability reported the periodic appearance of peaks consistent with the breakdown and release of myelinassociated macromolecules from MRI normal appearing parasagittal cortical gray matter. ${ }^{22}$ These abnormal cortical signals had a time course similar to that seen in acutely evolving lesions in the white matter, with the exception that associated alterations in Cho and NAA were not found. This MRSI pattern may be consistent with the pathologic finding that intracortical lesions show little perivenular inflammatory change, gliosis or substantial neuronal loss that accompanies their myelin loss and microglial activation. ${ }^{23}$ Other investigators report decreases in all measured metabolites including NAA in MS gray matter. ${ }^{102}$ Reduced NAA has also been documented in deep central gray structures consistent with neuronal loss and atrophy of these structures. ${ }^{12,113}$

Clinical correlation. When applied to patients across a broad range of clinical impairments, NAA/Cr ratios correlate moderately with disease duration and disability. ${ }^{105,114}$ Patients with RR MS and advanced clinical disability, those with SP MS, and patients with long disease duration generally show the most severe loss of NAA. Some evidence supports a disproportionate increase in $\mathrm{Cr}$ in patients with PP MS compared with those with RR MS, ${ }^{115}$ possibly reflecting more widespread gliosis in the former. Reductions in NAA and increased signal from lipids are also found in PP MS in a manner that is consistent with findings of widespread neuronal dysfunction in RR MS. ${ }^{116}$ Regional reductions in NAA correlate with cognitive dysfunction, ${ }^{117}$ and the extent of adaptive cortical reorganization for motor movements shown by functional imaging has been correlated with altered NAA/Cr ratios in the centrum semiovale. ${ }^{118} \mathrm{Re}$ ductions in NAA are associated with total T2 BOD, the extent of global tissue loss or atrophy, and the extent of tissue damage reflected by cerebral T1-hypointense lesion load. Whereas these are interrelated measures of tissue damage, the specificity of NAA for axonal dysfunction and axonal loss makes MRS the more intellectually appealing of these measures. ${ }^{119}$

Role in therapeutic monitoring. While highly attractive, the technical demands of spectroscopy have generally limited its use in therapeutic trials to single centers with conflicting results generally reported from small patient cohorts. IFNB has shown conflicting results on MRS parameters, including the ability to improve/stabilize $^{120}$ or have little effect ${ }^{121-123}$ on NAA content in MS cohorts. The small size of patient cohorts studied and the lack of parallel control groups likely contribute to these ambiguous results. However, attempts to monitor larger subcohorts of patients in multicenter trials have shown that this is feasible. ${ }^{116}$ Moreover, whole brain spectroscopy ${ }^{124}$ has been applied in several trials with reproducible longitudinal data obtained (M. Filippi, personal communication). However, no clinical effect was noted in one of these trials, making it difficult to know how sensitive the approach is to therapeutic interventions.

\section{Magnetization transfer imaging}

Technical aspects. An excellent review of the methodology of magnetization transfer imaging (MTI) has been published recently. ${ }^{125}$ MTI is an advanced quantitative MRI technique based on interactions and exchange between mobile protons in a free water pool with those bound to macromolecules. Only the mobile protons contribute to the signal intensity of the image, allowing for sensitivity to diffuse occult pathology such as demyelination, gliosis, and inflammation that may escape detection by conventional MRI. MTR can be obtained using either a gradient-echo or spin-echo pulse sequence. The preferred sequence is a $3 \mathrm{D}$ gradient-echo with a short $\mathrm{TE}$ at 1.5-T. Images are obtained with and without an MT saturation pulse. The pulse typically has frequency offset $1.2 \mathrm{Khz}$, bandwidth $400-600 \mathrm{~Hz}$, and flip angle/time between saturation pulses 25-35 degrees/ms. Two general methodologies have been used for analysis of MTR in MS. One involves global measurement of MTR calculated on a voxel-by-voxel basis throughout the whole 


\section{Magnetization Transfer Imaging}
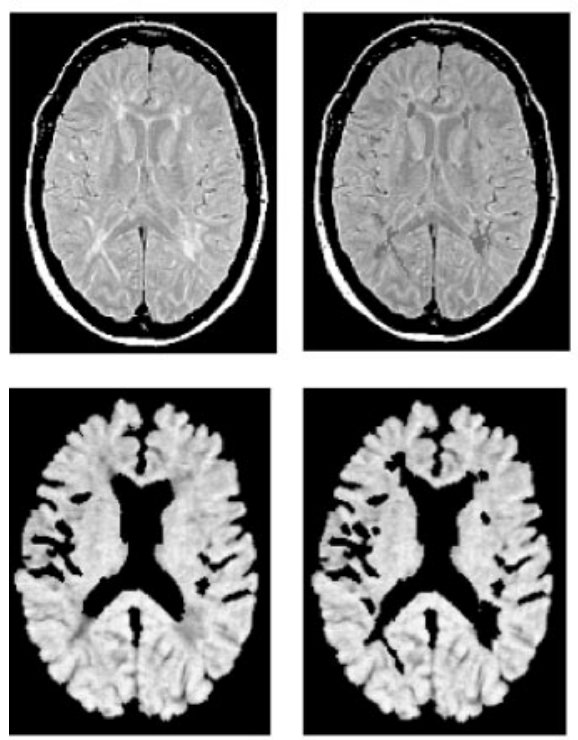

Registred \& segmented

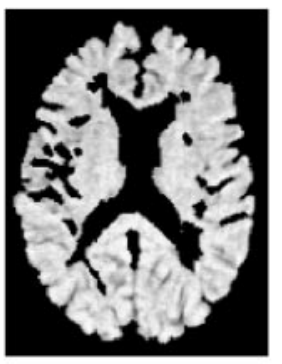

NABT

\begin{tabular}{lcccc} 
& $\begin{array}{c}\text { Controls } \\
\text { vs RRMS }\end{array}$ & vs PPMS & vs SPMS & $\begin{array}{c}\text { RRMS } \\
\text { vs BMS }\end{array}$ \\
\hline Average MTR & $<0.0001$ & 0.002 & n.s. & n.s. \\
Peak height & n.s. & 0.01 & 0.05 & n.s. \\
Peak position & $<0.0001$ & n.s. & n.s. & n.s. \\
\hline
\end{tabular}

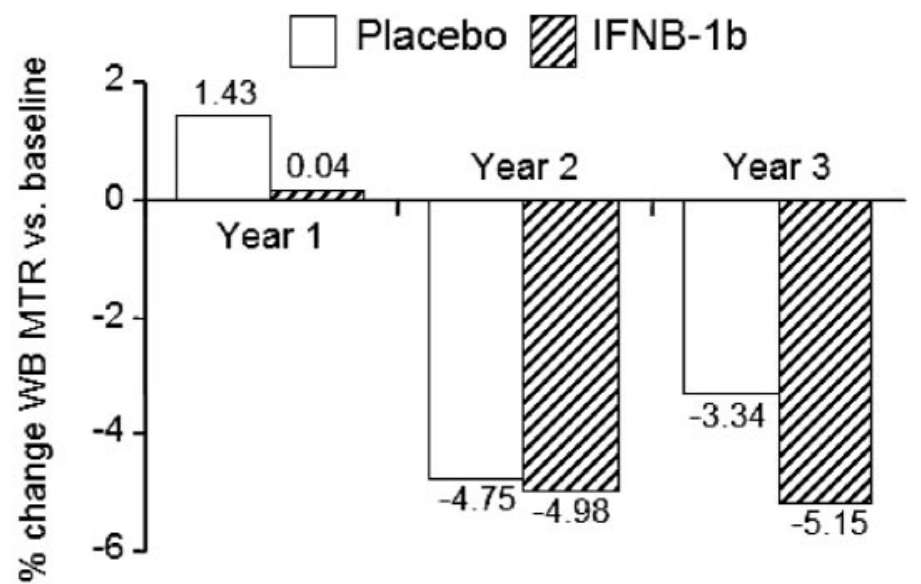

FIG. 5. MTR in normal appearing brain tissue (NABT) in MS. MRI scans are proton-density images (upper row) before (left) and after (right) masking of lesions and MTR maps coregistered to the source images and segmented to remove extracranial tissue and CSF, before (left) and after (right) masking of lesions. The upper right table is adapted with permssion from Tortorella et al. Magnetization transfer histogram study of normal-appearing brain tissue in MS. Neurology 54:186-193. Copyright $\odot 2000$. All rights reserved.259 It shows differences in MTR of NABT among MS and healthy controls groups. MS groups are: benign (BMS) RR MS, SP MS, and PP MS. n.s. = Nonsignificant. Lower right graph shows results of a published study ${ }^{152}$ on the lack of effect on interferon $\beta$ 1-b (IFNB-1b) on progressive reduction of MTR of NABT in patients with SP MS. Figure is courtesy of Massimo Filippi, M.D.

brain or within large areas of the brain free from lesions (normal appearing brain, white matter or gray matter). Another approach measures changes within lesions or other focused regions-of-interest. MTR data are typically expressed as histograms from which analysis is performed of the peak height, peak position, and mean.

Clinical correlation. The reader is referred to an excellent recent review of the full range of neurologic applications of this technique. ${ }^{126}$ Regarding the pathogenesis of MS, tissue damage is reflected by a decrease in this exchange of mobile and bound protons with reduction in MTR. MTI is emerging as a sensitive method to detect disease activity and monitor disease progression in MS. Early studies using MTR in an animal model ${ }^{127}$ and in patients with $\mathrm{MS}^{128,129}$ showed that decreased MTR was present and most likely reflected demyelination and axonal loss. However, reduced MTR is generally nonspecific and may be influenced by edema, gliosis, and inflammation. A number of groups have subsequently investigated MTR findings related to lesion genesis and evolution. ${ }^{13,14,130-135}$ These studies indicate that, on average, MTR declines a few months before Gd-enhancing lesions appear and then declines further when the lesion begins to enhance. The magnitude of decline of MTR during the time of enhancement predicts whether the lesion will evolve into a T1-hypointense lesion, indicating that the degree of MTR alteration is a marker of overall lesion severity. When initial MTR decreases are only modest, a partial or complete recovery of MTR is likely to occur in the next few months. This recovery of MTR values most likely reflects remyelination or other repair such as resolution of edema, gliosis, and inflammation. MTI has also been applied to study pathological changes in the areas of brain that are free from overt lesions on conventional MRI scans. The importance of detection of abnormalities in normal appearing brain tissue MS has recently been reviewed. ${ }^{136}$ Decreased MTR has been detected in the whole brain, ${ }^{137}$ NAWM,${ }^{138}$ and gray matter ${ }^{139}$ in patients with MS in comparison with normal controls (FIG. 5). The cervical cord ${ }^{140}$ and optic nerve ${ }^{141}$ also show decreased MTR in MS. 
The degree of decreased MTR varies among MS phenotypes and is thus related to disease course. ${ }^{142}$ Whereas MTR decreases are more profound in patients with progressive disease, such changes are also seen in RR MS and even at the occurrence of the initial attack (CIS). ${ }^{139}$ Decreases in MTR can predict the development of disease progression, such as accumulation of disability, in longitudinal studies. In a 4.5-year longitudinal study, Rovaris et al. ${ }^{143}$ assessed T2-hyperintense and T1-hypointense lesion volumes, normalized brain volume, average lesion MTR, and whole brain MTR in 73 patients with MS. A multivariate analysis showed that average brain MTR percentage change during the first year (odds ratio $[\mathrm{OR}]=0.86, p=0.02$ ) and baseline T2-hyperintense lesion volume $\mathrm{OR}=1.04, p=0.04$ ) were independent predictors of the accumulation of disability $(\mathrm{r} 2=0.23)$. Brain MTR showed a high specificity (76.9\%) and positive predictive value $(59.1 \%)$ for EDSS deterioration. Santos et al. ${ }^{144}$ in a 5 -year longitudinal study, similarly found a strong predictive value for baseline MTR values toward a 5-year change in disability. However, another group found that progressive decreases in MTR occurred despite stability of EDSS scores. ${ }^{145}$ MTR reductions are also related to cognitive impairment. ${ }^{146,147}$

Role in therapeutic monitoring. The potential role of MTI as an endpoint for treatment monitoring in MS has been the subject of several reviews, ${ }^{125,148,149}$ reflecting the growing interest in this potential biomarker. The enthusiasm for MTR as a longitudinal tool stems from its sensitivity to change in whole brain or NAWM that has been demonstrated in several studies in MS. ${ }^{14,143,145,150-153}$ Filippi et al. ${ }^{151}$ studied 96 patients with MS and 20 healthy subjects with MRI performed at baseline and again at follow-up 1 year later. They measured average lesion MTR, whole brain MTR, and MTR of normal-appearing brain tissue. In controls, there was no significant change of any MTR data. However, in the MS group, all MTR values decreased during the year. Patients with RR MS and SP MS had greater decreases in MTR metrics compared with CIS, benign MS, or PP MS groups. Patel et al. ${ }^{145}$ measured whole brain MTR in 20 patients with RR MS at baseline and again at follow-up at 1-4 years, and showed a significant longitudinal decline.

Data are accumulating on the sensitivity of MTR as a tool to assess treatment effects in MS..$^{13,149,150,152-155}$ Richert et al. ${ }^{150}$ obtained serial monthly whole brain MTR in eight patients with RR MS in a crossover trial with IFNB-lb. When histograms were analyzed by quartiles, voxels with low MTR increased during the baseline period ( 6 months) and corresponded to bulk white matter lesion load. IFNB-lb attenuated Gd-enhancing lesions by $91 \%$ and T2 BOD by $15 \%$ but had no effect on MTR during the subsequent 6-month treatment period. Inglese et al. ${ }^{152}$ showed that MTR of the whole brain and NAWM declined over 4 years in a subset of patients from the European double-blind, placebo-controlled trial of IFB-1b in SP MS. In both the treatment and placebo arms, there was a decrease of whole brain MTR from baseline to month 24 (mean change $-4.9 \%$ ) and month 36 (mean change $-4.3 \%$ ). A decrease of NAWM MTR was also observed. There was no significant difference in change of MTR between the two treatment arms (FIG. 5). Besides the ability to monitor global changes, MTR may show treatment effects on lesion evolution. Richert et al. ${ }^{13}$ measured MTR in 225 Gd-enhancing lesions in four patients with RR MS for 12 months before and 12-18 months after contrast enhancement in a baseline versus treatment trial of IFNB-1b. After enhancement, lesion recovery on MTR was significantly higher for lesions treated with IFNB-1b or corticosteroids than untreated lesions, indicating that disease-modifying therapies affect lesion evolution as defined by MTR. Similarly, Kita et al. ${ }^{154}$ showed that weekly intramuscular IFNB-1a given to eight patients with RRMS accelerated the rate of recovery of lesion MTR on active therapy compared to the pretreatment phase.

In summary, MTI has expanded the ability to detect the subtle abnormalities of the brain and spinal cord of MS patients and has provided increased sensitivity to obtain relevant information on the structural alterations within and outside T2-weighted visible lesions. The broad use of MTI in MS patients has already improved the understanding of the mechanisms leading to irreversible disability and may potentially allow the assessment of the effects of treatments.

\section{Atrophy of the CNS}

Overview. Atrophy of the brain and spinal cord has long been recognized as part of the pathology of MS. However, for decades, this atrophic process was regarded as a late complication in MS. With a better understanding of the pathogenesis of MS, CNS atrophy and other destructive aspects of the disease occur early in the disease process, as recently reviewed. ${ }^{156,157}$ The etiology of CNS atrophy is likely multifactorial, although it remains speculative. ${ }^{80,156-159}$ It is believed that the inflammatory cascade in MS leads to oligodendrocyte injury, failure of remyelination, axonal loss, Wallerian degeneration, and contraction of glial tissue. Neuronal and axonal loss occurs on a large scale in MS and affects both white matter ${ }^{160}$ and gray matter. ${ }^{161}$ As recently reviewed, the rate of atrophy in MS varies over time ${ }^{157}$ and can be detected in the earliest stages of disease (i.e., in patients with CIS who later develop clinically definite MS). ${ }^{162}$ CNS atrophy is a progressive phenomenon that worsens with increasing disease duration and worsening disease course (FIG. 6). Measurable alterations in brain and spinal cord tissue volume have been demonstrated over periods as short as 6-12 months, and typically progress at a rate of approximately $0.6-1.2 \%$ loss of 


\section{Progressive Brain Atrophy in MS}

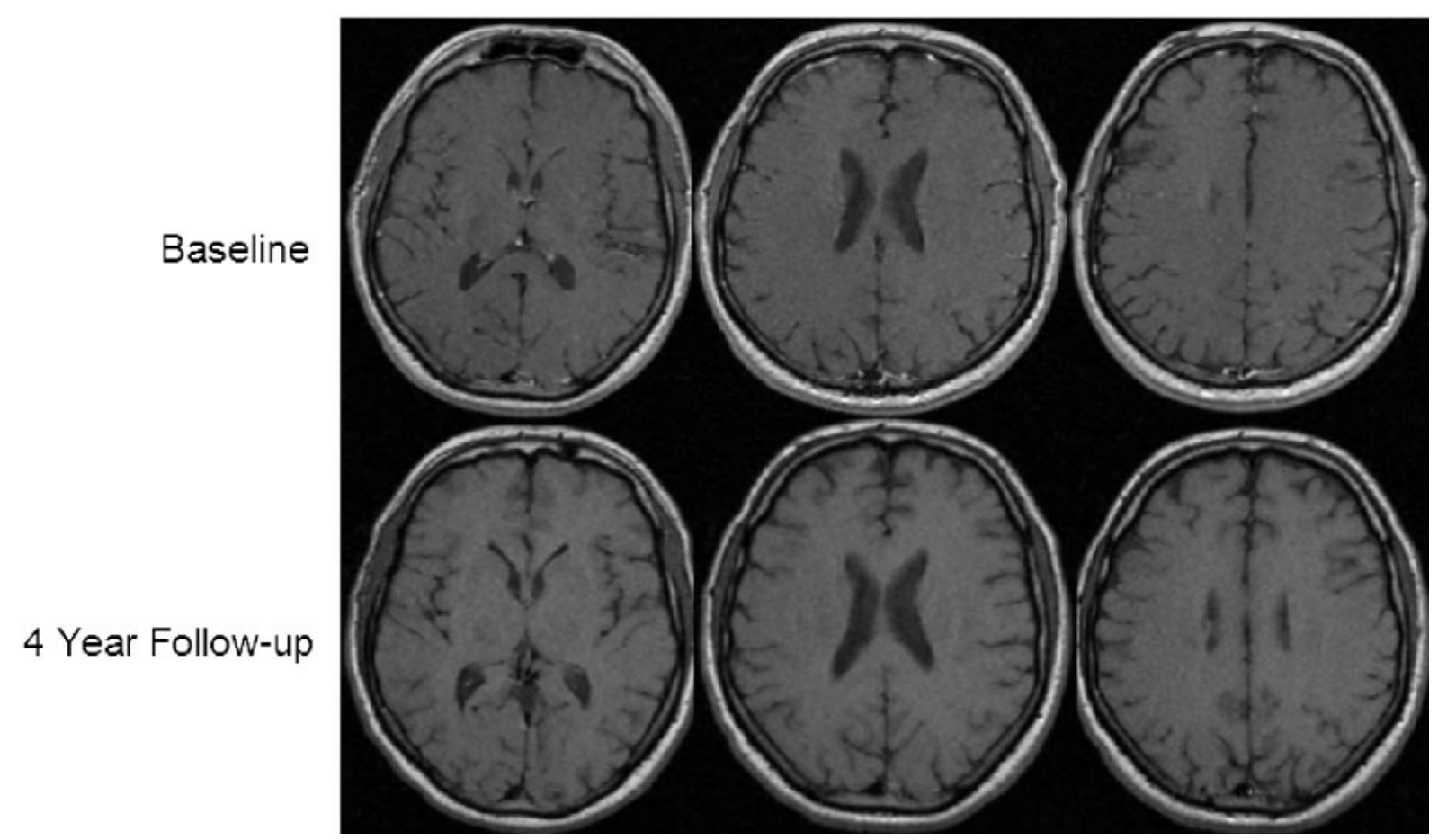

FIG. 6. Progressive brain atrophy in a 41-year-old man with RR MS imaged at baseline and 4 years later. Noncontrast T1-weighted images show progressive enlargement of the ventricles and subarachnoid spaces consistent with diffuse brain volume loss.

brain volume annually in patients with MS, with a fairly similar rate seen among RR, SP, and PP patients. ${ }^{157}$

Technical aspects. The reader is referred to recent comprehensive reviews of the methodologic challenges of measuring atrophy of the brain ${ }^{156,157,163,164}$ and spinal cord $^{156,157,165}$ in MS. Methods currently include: 1) regional linear (2D) measurements of portions of the CSF compartment, brain or spinal cord, 2) whole brain (3D) assessments of brain volume or fraction (FIGS. 7 and 8), and 3) regional 3D measurements of tissue or CSF compartments.

Clinical correlation. The reader is referred to several recent detailed reviews on the relationship between CNS atrophy in MS and cognitive impairment, ${ }^{166}$ physical disability, ${ }^{167}$ disease course, ${ }^{167}$ mood disturbances, ${ }^{166}$ and quality of life. ${ }^{167}$ Losseff et al. ${ }^{168}$ showed that progression of brain atrophy, but not T2-hyperintense lesions over 18 months, was related to deterioration of EDSS score. Dastidar et al. ${ }^{169}$ showed that brain atrophy was associated with EDSS score, whereas T2-hyperintense and T1-hypointense lesion volumes were not. Bermel et al. ${ }^{170}$ showed that whole brain atrophy was the best predictor of EDSS disability when compared with other cerebral lesion measures $\left(R^{2}=0.204, p<0.001\right)$. Fisher et al. ${ }^{171}$ showed that whole brain atrophy in the first 2 years was the best MRI predictor of the 8-year EDSS score after accounting for the 2-year change in conventional MRI lesions. Spinal cord atrophy is also related to disability in MS. Patients with spinal cord atrophy have higher levels of EDSS disability than those without atrophy $(p=0.006) .{ }^{172}$ Stevenson et al. ${ }^{173}$ showed that spinal cord atrophy, but not cerebral T2hyperintense or T1-hypointense lesions, correlated strongly with disability $(\mathrm{r}=-0.7 ; p<0.0001)$. Ingle et al. ${ }^{174}$ showed that spinal cord atrophy correlated with higher EDSS scores over 5 years $(\mathrm{r}=-0.31 ; p<0.05)$. Lin et al. ${ }^{175}$ showed that spinal cord atrophy closely predicts the development of progressive disability.

A number of studies have established an association between brain atrophy and cognitive impairment in MS patients. ${ }^{166}$ One of the first studies conducted in this area demonstrated that linear measures of brain atrophy (bifrontal span, bicaudate span, and third ventricle width) were significantly correlated with cognitive impairment. ${ }^{176}$ Subsequent work confirmed the close relationship between cognitive impairment and atrophy in central brain regions, measured by corpus callosum atrophy, ${ }^{177}$ the bicaudate ratio, ${ }^{178}$ and enlargement of the lateral ventricles. ${ }^{179}$ Furthermore, whole brain atrophy predicts cognitive impairment in both cross-sectional and longitudinal studies. ${ }^{180-182}$ Regarding the question as to whether atrophy or lesion measures are the strongest predictors of cognitive impairment, Benedict et al. ${ }^{182}$ performed neuropsychological testing and MRI in 37 
Whole Brain Segmentation
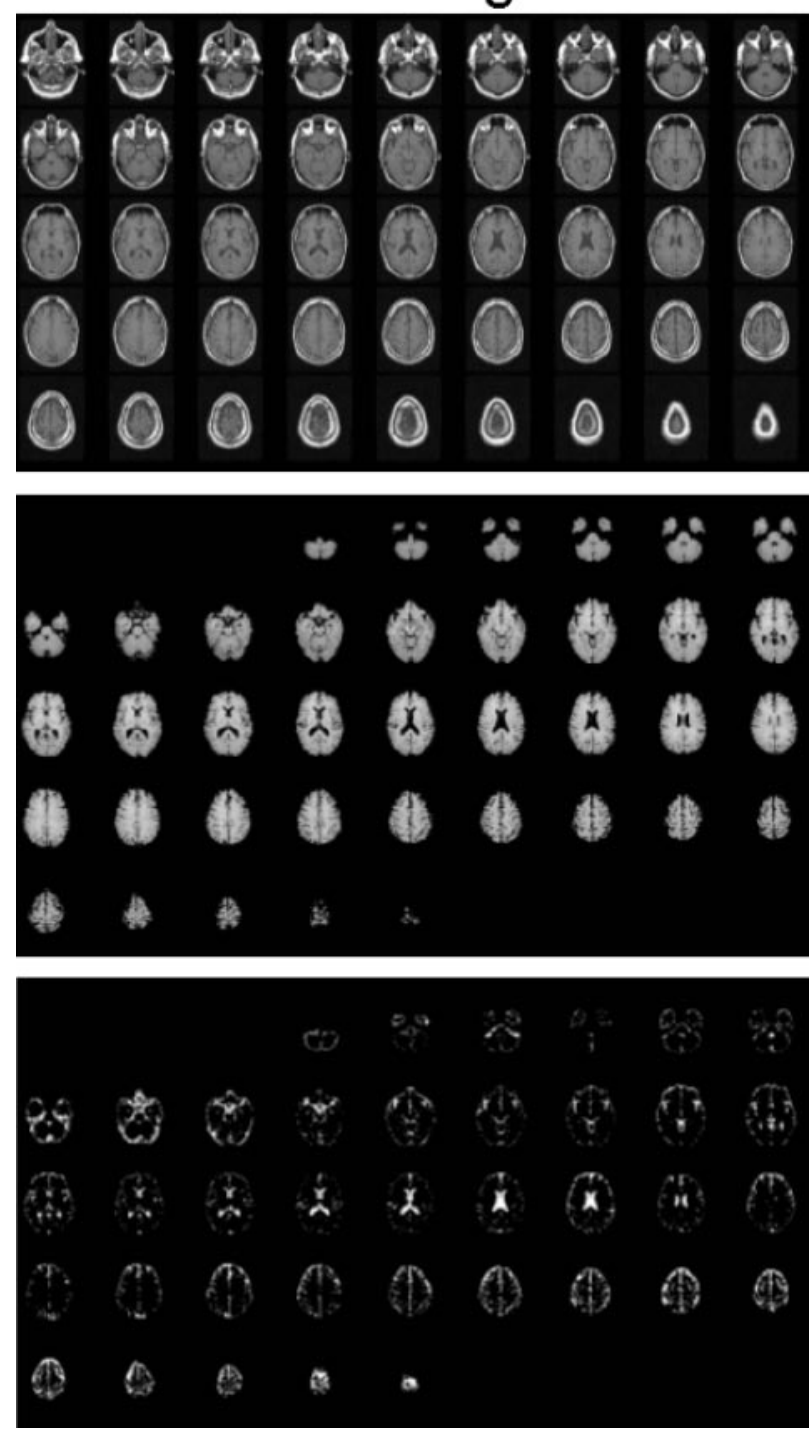

FIG. 7. A quantitative computer-assisted semiautomated meth$\mathrm{od}^{170}$ of measuring brain parenchymal fraction, a normalized measure of whole brain volume. Source images and processing of images is shown. The upper panel is the raw 2D T1-weighted noncontrast axial series. The middle panel is the same images after masking (removal) of extracranial tissue. The lower panel shows segmented images after thresholding separates the parenchyma (black) and CSF (white) into two compartments.

patients with RR $(\mathrm{n}=30)$ or SP MS $(\mathrm{n}=7)$. The quantitative MRI measures included whole brain FLAIRbased T2-hyperintense lesion load and T1-hypointense lesion load, bicaudate ratio, third ventricle width, and whole brain normalized volume. Regression modeling indicated that third ventricle width explained significant variance in information-processing speed and memory testing. When third ventricle width was removed from consideration, whole brain atrophy accounted for the most variance in these models. Emerging studies test the relative importance of gray or white matter atrophy ${ }^{183,184}$ and regional lobar atrophy ${ }^{185}$ in predicting cognitive impairment.

In summary, studies to date on the relationship between atrophy and clinical status in MS indicate that: 1) CNS atrophy predicts to a moderate degree the subsequent development of physical disability and cognitive impairment; 2) the relationship is independent of the effect of T2-hyperintense, T1-hypointense, or Gd-enhanced MRI lesions; and 3) spinal cord atrophy is particularly well correlated with motor disability while brain atrophy is particularly well correlated with neuropsychological impairment. Taken together, this body of data argues for tissue loss contributing to clinical findings to a greater extent than what is accounted for by conventional lesion measures.

Role in therapeutic monitoring. Several recent reviews are available on the role of CNS atrophy as a surrogate measure of therapeutic efficacy in MS. ${ }^{186,187}$ Several clinical trials have assessed the effects of disease-modifying agents: intramuscular IFNB-1a, subcutaneous IFNB-1a, IFNB-1b, and GA as well as methylprednisolone. These agents attenuate inflammatory components of the disease including clinical relapses and contrast-enhancing lesions. Because inflammation in MS has been linked to irreversible CNS tissue loss, these medications might be effective in reducing the rate of CNS atrophy.

Rudick et al. ${ }^{188}$ conducted a post hoc analysis of a 2-year placebo-controlled, phase III clinical trial of the effects of weekly intramuscular IFNB-1a in RR MS. Normalized brain volume was assessed in a subgroup of patients with available MRIs at baseline, and after 12 and 24 months of randomized treatment. The investigators reported that in the second year the rate of brain volume loss was attenuated by $55 \%$ in the treatment versus placebo group $(p=0.03)$. The effect of subcutaneous IFNB-1a three times a week on brain atrophy in RR MS was assessed in a post hoc analysis of MRI data from a 2-year placebo-controlled, phase III clinical trial. ${ }^{189}$ The study failed to demonstrate any significant beneficial effects of treatment on brain volume loss. Lack of effect of this same dosing strategy was suggested in an analysis of spinal cord atrophy in a subgroup of this cohort. ${ }^{175}$ However, in a clinical trial of patients with CIS, Filippi et al. ${ }^{162}$ showed a $30 \%$ reduction in the rate of whole brain volume loss over 2 years in patients receiving weekly subcutaneous IFNB-1a versus placebo $(p=$ 0.003).

Data on every-other-day subcutaneous IFNB 1-b have shown conflicting results with no effect seen in a 3-year placebo-controlled, phase III clinical trial of SP MS in the entire cohort, but an effect was seen on patients with no enhancing lesions at baseline $(p=0.0026) .{ }^{190}$ An open-label baseline-versus-treatment study in patients with RR MS compared brain volume change in the 6 


\section{Whole Brain Atrophy in MS}

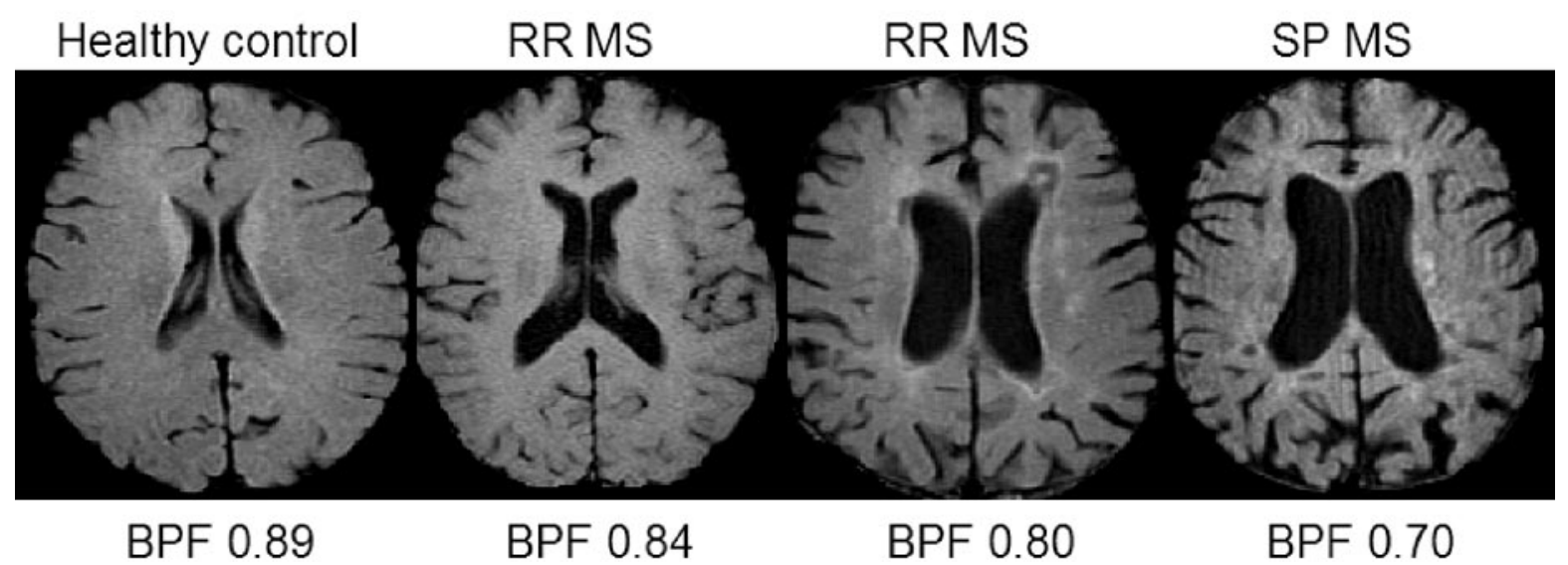

FIG. 8. Whole brain atrophy in MS as measured by brain parenchymal fraction (BPF) from Bakshi and colleagues. BPF is the ratio of the brain parenchyma to intracranial volume. Representative mid-ventricular axial noncontrast T1-weighted MRI scans are shown from age-matched individuals in the sixth decade. Note the progressive decrease in brain parenchyma, increase in CSF spaces, and decrease in BPF among the subjects from left to right in the figure. The first patient with RR MS has an EDSS score of 1.5 and disease duration (DD) of 5 years. The next patient with RR MS has an EDSS score of 4.0 and DD of 10 years. The patient with SP MS has an EDSS score of 6.5 and DD of 18 years.

months pretreatment with the brain volume change over 3 years after starting IFNB-1b. Brain volume decreased during the first year, was stable during the second year, then decreased during the third treatment year. ${ }^{191}$

The ability of GA to attenuate the progression of brain atrophy in MS was suggested by analyses of the North American placebo-controlled, phase III clinical trial of RR MS. ${ }^{192,193}$ Such effects were assessed more definitively by analyzing data from the European-Canadian placebo-controlled phase III clinical trial of $R R$ MS. ${ }^{194,195}$ The study showed a delayed treatment effect on reducing the rate of whole brain volume loss by $40 \%$ in the second 9 months $(p=0.015) .{ }^{195}$ When the data were analyzed by a less reproducible central 7-slice method for estimating brain atrophy, the treatment effect could not be detected. ${ }^{194}$ This highlights the importance of technical factors in the use of atrophy as a treatment outcome measure.

Zivadinov et al. ${ }^{196}$ performed a controlled, singleblind phase II trial of pulse intravenous methylprednisolone on disease course and MRI measures in RR MS. Active treatment was associated with preservation of brain volume over a 5 -year period, whereas the brain volume decreased significantly in control patients $(+1.3$ $v s-74.5 \mathrm{ml}, p=0.003)$.

In summary, MRI-based measurement of CNS atrophy is of growing interest in the therapeutic monitoring in MS. The limitations and challenges include the need to better understand the effect of reversible and nondisease factors on tissue volume loss such as of medications, fluid status, inflammation, and hormonal influences. ${ }^{197}$

\section{T1 and T2 shortening}

T1 shortening. Hyperintense cerebral lesions on noncontrast T1-weighted images, also referred to as areas of T1-shortening, have been described in a number of diseases ${ }^{198}$ and may reflect a variety of substances such as methemoglobin, proteinaceous material, lipids, free radicals, and paramagnetic metals such as non-heme iron. Remyelination has also been hypothesized to produce $\mathrm{T} 1$ shortening. ${ }^{199,200} \mathrm{~T} 1$ shortening has been described in MS lesions (FIG. 9). ${ }^{201,202}$ A retrospective MRI study of 145 patients with MS was conducted to determine the frequency, topography, and clinical correlation of $\mathrm{T} 1$ hyperintense lesions and to test the hypothesis that these lesions are related to cerebral atrophy. ${ }^{201} \mathrm{~T} 1$ hyperintense lesions occurred frequently (present in $78 \%$ of patients) and were confined to supratentorial regions. The lesions were more common in SP than RR MS. The lesions in each lobe showed moderate correlations with physical disability (EDSS) score $(\mathrm{r}=0.23-0.52, p<$ $0.0001)$ and brain atrophy. Further studies are necessary to determine the role of T1-shortening lesions in monitoring the MS disease process.

T2 shortening. Gray matter hypointensity on T2weighted images (T2 hypointensity or T2 shortening) is another category of abnormalities that can be detected by MRI in MS (FIG. 10). Because it is now widely accepted that MS is a "whole-brain" disease with gray and white matter involvement, these lesions have attracted more attention. T2 hypointensity occurs commonly in the cortical and subcortical gray matter in patients with RR or SP MS. ${ }^{203,204}$ In a quantitative cross-sectional MRI 


\section{T1 Shortening in MS Lesions}

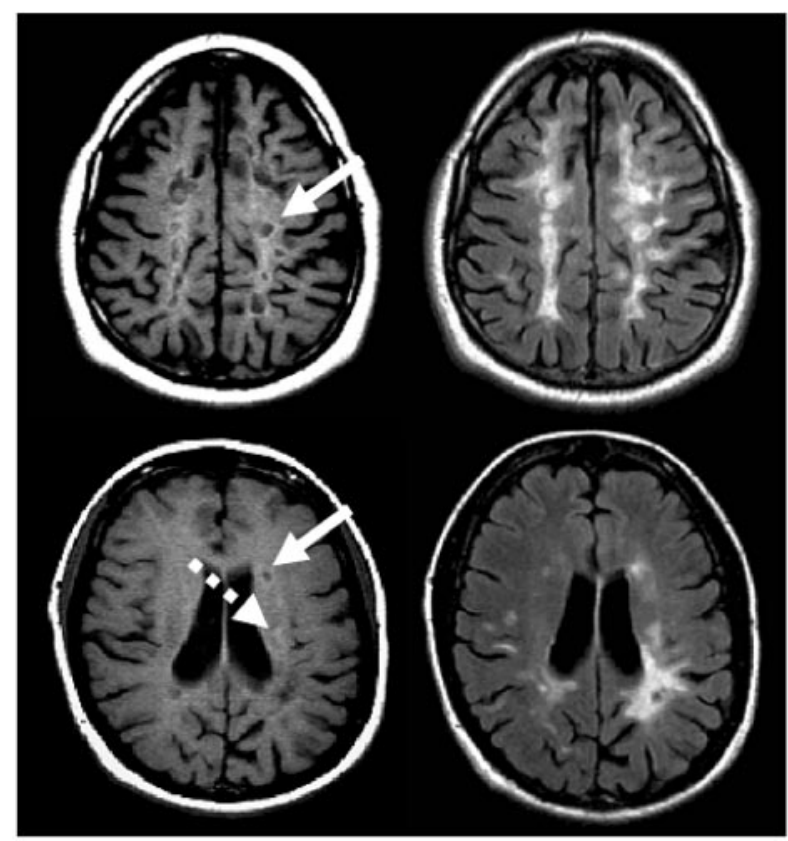

T1 non-contrast

FLAIR

FIG. 9. T1 shortening in MS lesions. Bright lesions on noncontrast T1-weighted MRI scans are shown in this montage of two patients. The anatomically matched FLAIR scans are shown on the right. Upper row: 44-year-old man with RR MS and EDSS score of 5.0. Lower row: 38-year-old woman with RR MS and EDSS score of 2.5. Note the T1-hyperintensity (arrows) of the periphery of some of the lesions.

study $^{205}$ of 60 patients with MS and 50 controls, deep gray matter $\mathrm{T} 2$ hypointensity was present in both cortical and subcortical gray matter areas in the MS group. T2 hypointensity was associated with enlargement of the third ventricle and higher T2 BOD. Gray matter T2 hypointensity was a more potent predictor of disability and clinical course than conventional MRI findings. T2 hypointensity has been linked most closely with brain atrophy in MS (FIG. 10), ${ }^{206,207}$ including the demonstration that baseline T2 hypointensity is the best MRI predictor of the subsequent development of whole brain atrophy over 2 years in patients with early RR MS. The relationship between $\mathrm{T} 2$ hypointensity and the progression of brain atrophy was demonstrated in placebotreated but not IFNB-1a treated patients, suggesting that T2 hypointensity may offer some ability to discern neurotherapeutic effects. ${ }^{207}$ However, further longitudinal studies are necessary to clarify whether $\mathrm{T} 2$ hypointensity has a role as a therapeutic marker.

$\mathrm{T} 2$ hypointensity likely reflects pathologic iron deposition. ${ }^{208}$ There are two possible explanations for how iron deposition might relate to the pathophysiology of the disease, each with its own therapeutic implications. First, iron accumulation may purely represent an epiphenomenon resulting from neurodegeneration that occurs in gray matter in MS. ${ }^{113,161}$ If so, T2 hypointensity may serve as a method for monitoring therapeutic effects on the neurodegenerative component of the disease. Second, iron may participate directly in the pathogenesis of MS by promoting the generation of free radicals, oxidative stress, lipid peroxidation, and neurotoxicity. ${ }^{209}$ This would open new avenues such as iron chelators, antioxidants, and free radical scavengers, as potential agents for the treatment of MS, as has been suggested by animal studies. $^{210,211}$

\section{Diffusion-weighted imaging}

Technical aspects. Diffusion-weighted imaging (DWI) allows for the quantification of diffusional motion of water molecules. ${ }^{212}$ The technique can also provide detailed information on white matter fibers of the CNS using a variation known as diffusion tensor imaging (DTI) (FIG. 11). In human brain, diffusion is influenced by the microenvironment of CNS tissue including cell membranes, cell organelles and axons. DWI is sensitive to pathological processes that alter tissue integrity and result in changes in the permeability of barriers limiting water molecular motion and thereby affecting tissue anisotropy. Fractional anisotropy (FA), which is derived from DWI, is another useful measure that indicates the structural integrity and extent of structural alignment within fiber tracts. ${ }^{212}$ The reader is referred to a separate review in this volume that discusses the methodology of DWI in more detail. ${ }^{212}$ DWI is sensitive to the inflammatory changes that occur in the pathogenesis of MS. ${ }^{213,214}$ Cerebral lesions in MS typically manifest as

\section{T2 Hypointensity in MS}

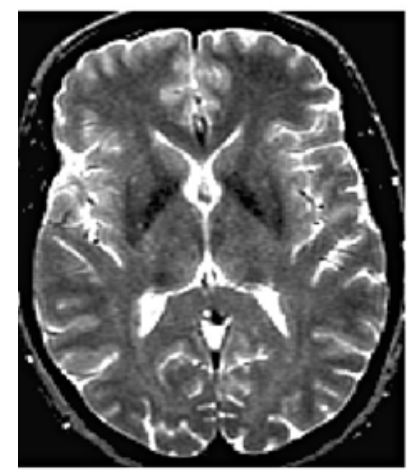

Healthy Control

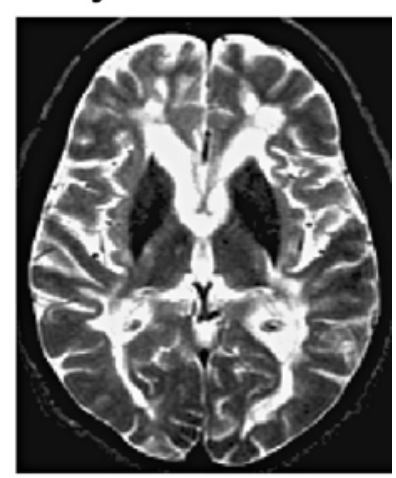

MS
FIG. 10. T2 hypointensity and brain atrophy in MS. Hypointensity on T2-weighted images has been described in the gray matter of patients with MS and is related to physical disability, cognitive dysfunction, clinical course, MRI lesion load, and brain atrophy. The T2 hypointensity most likely represents pathologic iron deposition. CSE T2-weighted images are shown of a 44year-old normal volunteer and an age-matched patient with RR MS (EDSS 5.0). In the latter, note the marked hypointensity of the deep gray matter nuclei, including the thalamus, caudate, and putamen. The patient also has brain volume loss compared to the control (note prominence of ventricular and subarachnoid spaces). 


\section{Diffusion Tensor Imaging}

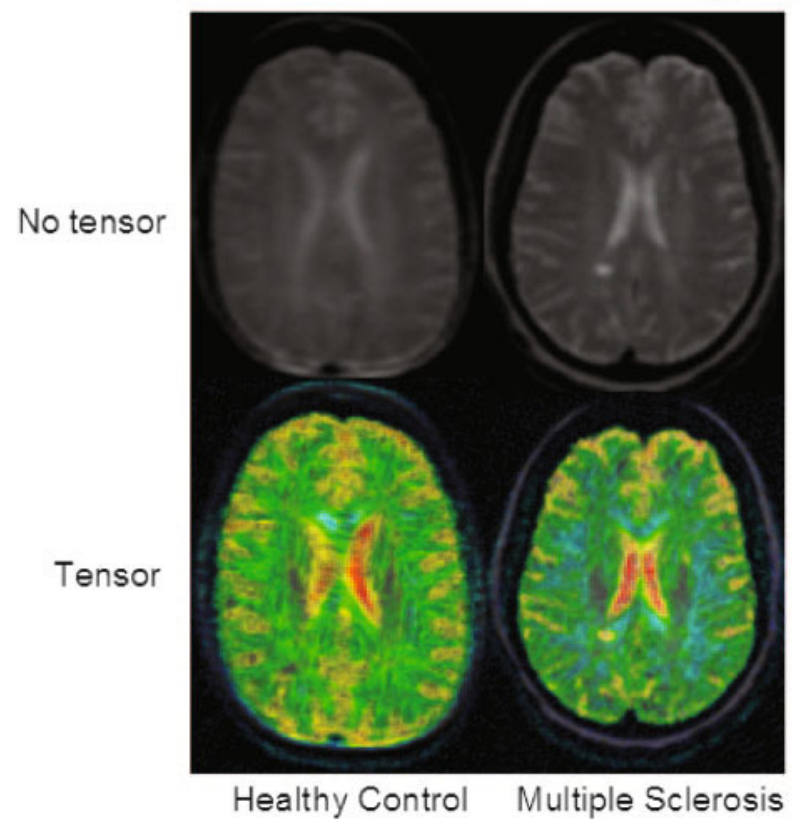

FIG. 11. Diffusion tensor imaging in MS. A 25-year-old healthy woman and a 42-year-old woman with RR-MS with low disability (EDSS score $=1$ ) are shown. The top row depicts the $b=0$ image, showing a white matter lesion in the patient's image. The bottom row shows glyphs representing the diffusion tensors, color coded by the degree of isotropy of the local diffusion tensor: red where the diffusion is most isotropic, and blue where the diffusion is most anisotropic. Note the increased isotropic diffusion in the region of the white matter lesion. Figure provided by Simon K. Warfield and Daniel Goldberg-Zimring.

hyperintense on DWI scans due to T2 shine through effects, which can be separated from true restriction of diffusion using apparent diffusion coefficient (ADC) maps. Lesions typically show increased diffusivity and increased ADC; the ADC is especially high in contrast enhancing lesions ${ }^{215}$ and T1-hypointense lesions. The increased diffusivity, increased ADC, and decreased FA is most likely nonspecific for the underlying pathology and reflects a variety of tissue changes such as demyelination, gliosis, inflammation, axonal contraction, and axonal loss. In addition to the study of individual lesions, ${ }^{20,216-220}$ DWI offers the opportunity to study global changes in NAWM ${ }^{21,216-218,221-225}$ and gray matter ${ }^{221,226,227}$ similar to the general approaches used with MTI. In addition, with DTI, the effect of MS on white matter fiber tracts can be examined (FIG. 11). ${ }^{21,223,224,228}$

Clinical correlation. There is growing interest in studying the relationship between DWI-related data and clinical manifestations of MS such as physical disability, disease course and cognitive impairment. Schmierer et al. ${ }^{225}$ measured the diffusion in normal-appearing brain tissue of 15 patients with PP MS over 1 year. In contrast to healthy subjects, patients developed increased ADC in the NAWM. Frontal ADC was associated with disability as measured by the MS Functional Composite Score. Ciccarelli et al. ${ }^{221}$ performed DTI in 39 patients with MS and found that FA and mean diffusivity in the cerebral peduncles were inversely correlated with the EDSS and pyramidal functional scores. In patients with RR MS, there was a strong correlation between EDSS score and FA in both supratentorial and infratentorial NAWM. Wilson et al. ${ }^{228}$ mapped the pyramidal tracts with DWI in 25 patients with RR MS and 17 healthy volunteers. Loss of tract integrity was present in patients but not controls. Pyramidal tract DTI data correlated significantly with both EDSS score $(\mathrm{r}=-0.48, p<0.05)$, and the pyramidal functional system score $(\mathrm{r}=-0.75, p<$ 0.0001 ), whereas whole brain T2 BOD and global diffusion histograms did not correlate with disability. Caramia et al. ${ }^{229}$ performed serial MRI including DWI over 1 year in 19 patients with CIS. Thirteen patients developed MS during the study. ADC in NAWM was significantly higher in patients than in healthy controls at 12 months follow-up but not at baseline $(p<0.02)$. Changes in ADC were related to changes in EDSS score $(p<0.01)$. Studies from another group have similarly shown a moderate relationship between DWI metrics and disability in MS. ${ }^{230,231}$ However, not all studies find significant correlations. ${ }^{232}$ DWI metrics have also been related to cognitive impairment in MS, although little work has been done in this area. Rovaris et al. ${ }^{227}$ studied 34 patients with RR MS, nine of whom were found to have cognitive impairment. Moderate correlations were found between cognitive tests and various MRI measures (T2-hyperintense lesion volume, T1-hypointense lesion volume, and diffusion measures -(average lesion, whole brain, and normal appearing tissue) with $r$ values ranging from -0.30 to -0.53 . No correlations were found between cognition and whole brain volume.

Role in therapeutic monitoring. DWI appears sensitive to dynamic disease-related changes. Rocca et al. ${ }^{222}$ obtained weekly DWI scans for 12 weeks from six patients. Areas of NAWM that later developed overt lesions showed a significant increase in mean diffusivity values beginning 6 weeks before $\mathrm{Gd}$ enhancement. Werring et al. ${ }^{218}$ similarly showed a steady and moderate increase in ADC in prelesion NAWM, which was followed by a rapid and marked increase at the time of $\mathrm{Gd}$ enhancement and a decay after the resolution of enhancement. These findings indicate that new inflammatory lesions are preceded by subtle, progressive alterations in diffusion. Cassol et al. ${ }^{224}$ performed DTI every 3 months in seven MS patients and seven controls. The MS group showed higher diffusivity and lower FA than normal controls in the whole supratentorial white matter. During the follow-up, the DWI measures progressed in the patients with SP MS. Schmierer et al. ${ }^{225}$ showed progressive increases in ADC of the normal-appearing brain tissue in 15 patients with PPMS over 1 year. Caramia et 


\section{Positron Emission Tomography}

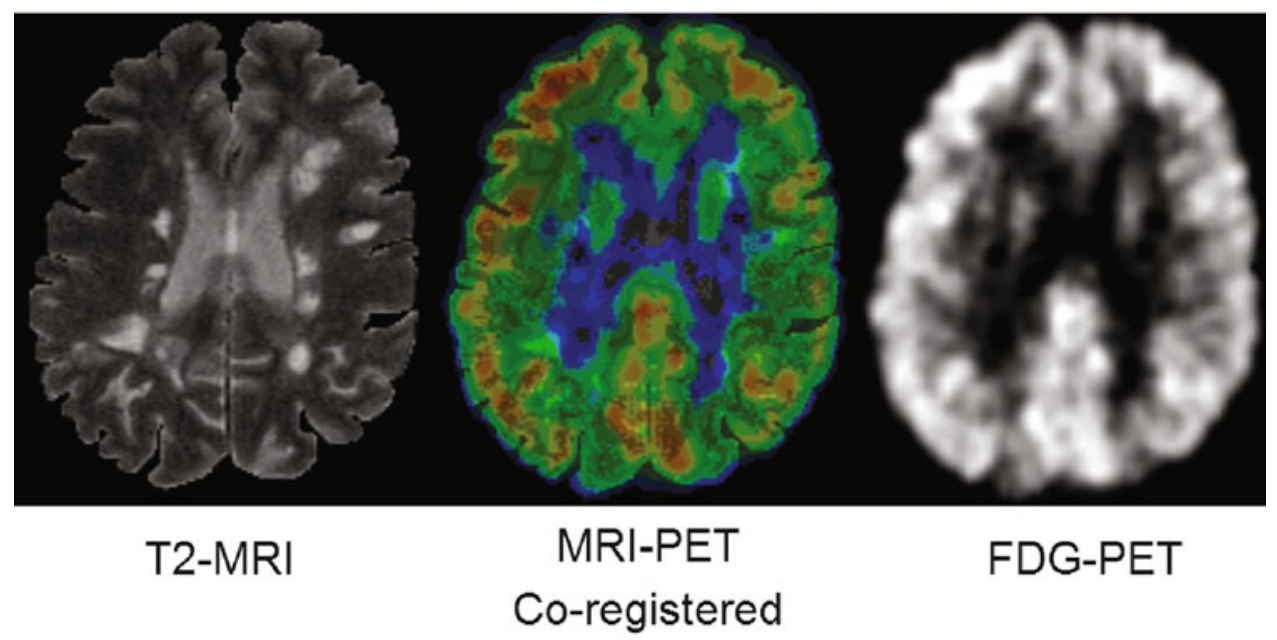

FIG. 12. PET imaging in MS. A patient with RR MS underwent MRI and fluorodeoxyglucose (FDG) PET of the brain. The T2-weighted MRI scan was coregistered with the FDG PET scan. A representative axial slice shows the source T2-weighted MRI scan (left) source FDG PET scan (right) and the resulting map obtained after 3D MRI-PET coregistration (middle). Glucose metabolism is displayed on a color scale (red is highest). Note the hypometabolism of the overt MRI lesions but also widespread hypometabolism of areas appearing normal on MRI in the cortical gray and subcortical white matter. Images are from Bakshi, Miletich, Kinkel, and colleagues.

al. ${ }^{229}$ showed that global diffusion abnormalities in the NAWM occurred at the earliest stage of MS, in patients with CIS followed for 1 year. The demonstration of longitudinal changes in diffusion in patients with MS creates the potential for the use of DWI as a treatment outcome measure. However, DWI correlations of treatment effects have not been the subject of any published studies to date.

\section{FUNCTIONAL IMAGING}

\section{Technical aspects}

The functional imaging modalities considered potentially relevant to neurotherapeutics in MS include positron emission tomography (PET), single-photon emission computed tomography (SPECT), and functional MRI (fMRI). The reader is referred to separate reviews in the current volume on the technical aspects and broad clinical applications of these modalities. ${ }^{212,233,234}$ PET and SPECT are nuclear imaging techniques based on radiolabeling of physiologic tracers that are usually administered intravenously and then imaged upon uptake into the brain. Examples include agents that measure perfusion or metabolism at the cellular level, peptides that assess synaptic function, and receptor-specific ligands that are markers for inflammatory or glial activity. The current journal volume contains extensive reviews on the technical aspects of PET and SPECT. ${ }^{233,234}$ In fMRI, brain activation in response to applied motor or visual stimuli is assayed by alterations in signal intensity that result from changes in blood levels of deoxyhemoglobin. fMRI can be used to detect functional reorganization in response to brain injury.

\section{Clinical correlation}

Application of PET and SPECT in MS has shown both regional and global reductions in basal cerebral metabolism and blood flow (FIG. 12) ${ }^{235-240}$ as well as altered cerebral activation with task performance. ${ }^{241}$ Bakshi et $\mathrm{al}^{237}$ performed high-resolution fluorodeoxyglucose PET in 25 patients with MS compared with healthy subjects. A 9\% reduction in whole brain glucose metabolism was noted in the MS group $(p<0.05)$. Hypometabolism was widespread, affecting the cortical and deep central gray matter, supratentorial white matter, and infratentorial structures. The most dramatic reductions were seen in the superior mesial frontal cortex, superior dorsolateral frontal cortex, mesial occipital cortex, lateral occipital cortex, deep inferior parietal white matter, and pons. The gray matter hypometabolism most likely represents a combination of direct gray matter involvement and diaschisis (neuronal system disconnection) resulting from white matter disease. Metrics derived from PET or SPECT have shown significant moderate correlations with relapse rate, ${ }^{238}$ physical disability, ${ }^{238}$ cognitive impairment, ${ }^{236,238,240}$ depression, ${ }^{235}$ and fatigue ${ }^{242}$ in MS. These functional imaging measures have shown a better correlation with clinical status than do conventional MRI lesion parameters.

Another use of nuclear imaging studies is ligand-based tracking of inflammatory cells in the CNS. ${ }^{243-245}$ This strategy has been applied to MS using [11C]PK11195, a compound that binds to the peripheral benzodiazepine receptor expressed on activated microglia. Vowinckel et al. ${ }^{245}$ found a correlation between PK11195 binding and immunoreactivity for microglial/macrophages at sites of 
inflammatory lesions in an animal model of MS, particularly at the edges of chronic active plaques. They further demonstrated by brain PET that [11C]-PK11195 accumulated only at sites of active MRI lesions in patients with MS. Banati et al. ${ }^{243}$ confirmed that activated microglia/macrophages are the main cell type expressing the peripheral benzodiazepine binding site at sites of active CNS pathology. They also found that [(11)C]PK11195 PET uptake extended to areas appearing normal on conventional MRI scans such as cerebral central gray matter. Debruyne et al. $^{244}$ showed that [11C]PK11195 uptake increased during a clinical or MRI-defined relapse, particularly in NAWM.

The scientific literature reflects an expanding interest in fMRI in MS. ${ }^{246-256}$ The major themes emerging from this body of work include: 1) increased magnitude or regional extent of activation during task performance occurs at the early stages of MS, including CIS, and is most likely adaptive (compensatory); 2) increased activation may include both ipsilateral and contralateral cortices on the basis of synaptic reorganization, recruitment of parallel existing pathways, and reorganization of distant sites; 3) the degree of fMRI abnormalities is correlated with lesion burden assessed by conventional MRI, supporting the notion that functional changes represent progressive consumption of cerebral reserve capacity; 4) as the disease worsens and brain reserve capacity is exceed, patients show decreased activation than earlier in the disease process; and 5) the magnitude of fMRI abnormalities is related to both physical disability and cognitive impairment. However, the relationship varies according to stage of disease.

\section{Role in therapeutic monitoring}

Functional imaging can detect dynamic changes related to intrinsic disease effects or therapeutic intervention. A longitudinal study ${ }^{239}$ compared PET and MRIbased surrogates in 10 patients over 2 years. Global cortical hypometabolism was progressive as was T2 BOD. However, MRI changes were not correlated with PET findings, suggesting that the latter was capturing unique aspects of disease progression. Mackowiak et al. ${ }^{257}$ used SPECT to determine the effect of IFNB-1b on cerebral blood flow five patients with MS. They found that the drug led to a significant increase in blood flow in the basal ganglia 6 hours after drug administration. Further study is necessary to determine the role of nuclear imaging as a biomarker of therapeutic efficacy. fMRI has shown potential in capturing treatment-related effects in MS. Parry et al. ${ }^{250}$ performed fMRI during the Stroop cognitive task in 10 patients and 11 healthy controls. The investigators observed that the left medial prefrontal region was more active in patients during the task, compared with the normal controls. In five patients, administration of the cholinergic agent rivastigmine was associated with relative normalization of the task specific fMRI brain activation pattern. No alterations in brain activation were observed among normal controls with rivastigmine. Although further studies are warranted, these initial findings suggest that fMRI can detect metabolic effects of symptomatic MS therapy. It remains to be determined how immunodulatory agents alter these abnormalities.

\section{Animal imaging}

MRI has been extensively applied to study various aspects of pathogenesis as well as histopathology of animal models of MS. The reader is referred to a comprehensive review of animal imaging, presented separately in this volume, which includes a discussion of MS-related work. ${ }^{258}$

Acknowledgments: The authors thank Sophie Tamm and Erika Balajti for technical support. Dr. Bakshi is funded by research grants from the National Institutes of Health (NIHNINDS 1 K23 NS42379-01) and the National Multiple Sclerosis Society (RG 3574A1). Dr. Wolinsky receives support from the NIH-NINDS (RO1-NS31499, U01 NS045719), The Clayton Foundation for Research, Sanofi Aventis Pharmaceuticals Inc., and Merck \& Co., Inc.

\section{REFERENCES}

1. McDonald WI, Compston A, Edan G, Goodkin D, Hartung HP, Lublin FD, et al. Recommended diagnostic criteria for multiple sclerosis: Guidelines from the International Panel on the Diagnosis of Multiple Sclerosis. Ann Neurol 121-127, 2001.

2. Miller DH, Filippi M, Fazekas F, Federiksen JL, Matthews PM, Montalban X, et al. Role of magnetic resonance imaging within diagnostic criteria for multiple sclerosis. Ann Neurol 56:273-278, 2004.

3. Barkhof F, Rocca M, Francis G, Van Waesberghe JH, Uitdehaag $\mathrm{BM}$, Hommes OR, et al. Validation of diagnostic magnetic resonance imaging criteria for multiple sclerosis and response to interferon $\beta 1$ a. Ann Neurol 53:718-724, 2003.

4. Zivadinov R, Bakshi R. Role of MRI in multiple sclerosis I: inflammation and lesions. Front Biosci 9:665-683, 2004.

5. Lai M, Hodgson T, Gawne-Cain M, Webb S, MacManus D, McDonald WI, et al. A preliminary study into the sensitivity of disease activity detection by serial weekly magnetic resonance imaging in multiple sclerosis. J Neurol Neurosurg Psychiatry 60:339-341, 1996.

6. Bakshi R, Hutton GJ, Miller JR, Radue EW. The use of magnetic resonance imaging in the diagnosis and long-term management of multiple sclerosis. Neurology 63(Suppl 5):S3-S11, 2004

7. Bagnato F, Jeffries N, Richert ND, Stone RD, Ohayon JM, McFarland HF, et al. Evolution of T1 black holes in patients with multiple sclerosis imaged monthly for 4 years. Brain 126:17821789,2003

8. Filippi M, Rovaris M, Rocca MA, Sormani MP, Wolinsky JS, Comi G. Glatiramer acetate reduces the proportion of new MS lesions evolving into "black holes." Neurology 57:731-733, 2001.

9. Barkhof F, Bruck W, De Groot CJ, Bergers E, Hulshof S, Geurts $\mathrm{J}$, et al. Remyelinated lesions in multiple sclerosis: magnetic resonance image appearance. Arch Neurol 60:1073-1081, 2003.

10. Masdeu JC, Quinto C, Olivera C, Tenner M, Leslie D, Visintainer P. Open-ring imaging sign: highly specific for atypical brain demyelination. Neurology 54:1427-1433, 2000.

11. Wolinsky JS, Narayana PA, Noseworthy JH, Lublin FD, Whitaker JN, Linde A, et al. Linomide in relapsing and secondary progressive MS: part II: MRI results. MRI Analysis Center of the 
University of Texas-Houston, Health Science Center, and the North American Linomide Investigators. Neurology 54:1734$1741,2000$.

12. Filippi M, Wolinsky JS, Sormani MP, Comi G, European Canadian Glatiramer Acetate Study Group. Enhancement frequency decreases with increasing age in relapsing-remitting multiple sclerosis. Neurology 56:422-423, 2001

13. Richert ND, Ostuni JL, Bash CN, Leist TP, McFarland HF, Frank JA. Interferon $\beta-1 \mathrm{~b}$ and intravenous methylprednisolone promote lesion recovery in multiple sclerosis. Mult Scler 7:49-58, 2001.

14. Laule C, Vavasour IM, Whittall KP, Oger J, Paty DW, Li DK, et al. Evolution of focal and diffuse magnetisation transfer abnormalities in multiple sclerosis. J Neurol 250:924-931, 2003.

15. Narayana PA, Doyle TJ, Lai D, Wolinsky JS. Serial proton magnetic resonance spectroscopic imaging, contrast- enhanced magnetic resonance imaging, and quantitative lesion volumetry in multiple sclerosis. Ann Neurol 43:56-71, 1998.

16. Tartaglia MC, Narayanan S, De Stefano N, Arnaoutelis R, Antel $\mathrm{SB}$, Francis SJ, et al. Choline is increased in pre-lesional normal appearing white matter in multiple sclerosis. J Neurol 249:13821390, 2002.

17. Wolinsky JS, Narayana PA. Magnetic resonance spectroscopy in multiple sclerosis: window into the diseased brain. Curr Opin Neurol 15:247-251, 2002.

18. Helms G, Stawiarz L, Kivisakk P, Link H. Regression analysis of metabolite concentrations estimated from localized proton MR spectra of active and chronic multiple sclerosis lesions. Magn Reson Med 43:102-110, 2000.

19. van Waesberghe JH, Kamphorst W, De Groot CJ, van Walderveen MA, Castelijn JA, Ravid R, et al. Axonal loss in multiple sclerosis lesions: magnetic resonance imaging insights into substrates of disability. Ann Neurol 46:747-754, 1999.

20. Castriota-Scanderbeg A, Fasano F, Hagberg G, Nocentini U, Filippi M, Caltagirone C. Coefficient $\mathrm{D}(\mathrm{av})$ is more sensitive than fractional anisotropy in monitoring progression of irreversible tissue damage in focal nonactive multiple sclerosis lesions. AJNR Am J Neuroradiol 24:663-670, 2003.

21. Henry RG, Oh J, Nelson SJ, Pelletier D. Directional diffusion in relapsing-remitting multiple sclerosis: a possible in vivo signature of Wallerian degeneration. J Magn Reson Imaging 18:420-426, 2003.

22. Sharma R, Narayana PA, Wolinsky JS. Grey matter abnormalities in multiple sclerosis: proton magnetic resonance spectroscopic imaging. Mult Scler 7:221-226, 2001.

23. Bo L, Vedeler CA, Nyland H, Trapp BD, Mork SJ. Intracortical multiple sclerosis lesions are not associated with increased lymphocyte infiltration. Mult Scler 9:323-331, 2003.

24. Lucchinetti C, Bruck W, Parisi J, Scheithauer B, Rodriguez M, Lassmann H. Heterogeneity of multiple sclerosis lesions: implications for the pathogenesis of demyelination. Ann Neurol 47: 707-717, 2000.

25. Stewart WA, Hall LD, Berry K, Paty DW. Correlation between NMR scan and brain slice data in multiple sclerosis. Lancet 2:412, 1984

26. Moore GR, Leung E, MacKay AL, Vavasour IM, Whittall KP, Cover KS, et al. A pathology-MRI study of the short-T2 component in formalin-fixed multiple sclerosis brain. Neurology 55: 1506-1510, 2000.

27. Bo L, Geurts JJ, Ravid R, Barkhof F. Magnetic resonance imaging as a tool to examine the neuropathology of multiple sclerosis. Neuropathol Appl Neurobiol 30:106-117, 2004.

28. Schmierer K, Scaravilli F, Barker GJ, Gordon R, MacManus DG, Miller DH. Stereotactic co-registration of magnetic resonance imaging and histopathology in post-mortem multiple sclerosis brain. Neuropathol Appl Neurobiol 29:596-601, 2003.

29. Newcombe J, Hawkins CP, Henderson CL, Patel HA, Woodroofe MN, Hayes GM, et al. Histopathology of multiple sclerosis lesions detected by magnetic resonance imaging in unfixed postmortem central nervous system tissue. Brain 114:1013-1023, 1991.

30. Bakshi R, Benedict RHB, Bermel RA, Jacobs L. Regional brain atrophy is associated with physical disability in multiple sclero- sis: semiquantitative MRI and relationship to clinical findings. J Neuroimaging 11:129-136, 2001.

31. Rovaris M, Comi G, Ladkani D, Wolinsky JS, Filippi M. Shortterm correlations between clinical and MR imaging findings in relapsing-remitting multiple sclerosis. AJNR Am J Neuroradiol 24:75-81, 2003.

32. Barkhof F. MRI in multiple sclerosis: correlation with expanded disability status scale (EDSS). Mult Scler 5:283-286, 1999.

33. Comi G, Filippi M, Barkhof F, Durelli L, Edan G, Fernandez O, et al. Effect of early interferon treatment on conversion to definite multiple sclerosis: a randomised study. Lancet 357:1576-1582, 2001.

34. Brex PA, Ciccarelli O, O'Riordan JI, Sailer M, Thompson AJ, Miller DH. A longitudinal study of abnormalities on MRI and disability from multiple sclerosis. $N$ Engl J Med 346:158-164, 2002.

35. Filippi M, Horsfield MA, Morrissey SP, MacManus DG, Rudge $\mathrm{P}, \mathrm{McD}$ nald WI, et al. Quantitative brain MRI lesion load predicts the course of clinically isolated syndromes suggestive of multiple sclerosis. Neurology 44:635-641, 1994.

36. O'Riordan JI, Thompson AJ, Kingsley DP, MacManus DG, Kendall BE, Rudge $\mathrm{P}$, et al. The prognostic value of brain MRI in clinically isolated syndromes of the CNS. A 10-year follow-up. Brain 121:495-503, 1998.

37. Fazekas F, Barkhof F, Filippi M, Grossman RI, Li DK, McDonald WI, et al. The contribution of magnetic resonance imaging to the diagnosis of multiple sclerosis. Neurology 53:448 -456, 1999.

38. Brex PA, Miszkiel KA, O'Riordan JI, Plant GT, Moseley IF, Thompson AJ, et al. Assessing the risk of early multiple sclerosis in patients with clinically isolated syndromes: the role of a follow up MRI. J Neurol Neurosurg Psychiatry 70:390-393, 2001.

39. Dalton CM, Brex PA, Miszkiel KA, Fernando K, MacManus DG, Plant GT, et al. New T2 lesions enable an earlier diagnosis of multiple sclerosis in clinically isolated syndromes. Ann Neurol 53:673-676, 2003.

40. Jacobs LD, Beck RW, Simon JH, Kinkel RP, Browscheidle CM, Murray TJ, et al. Intramuscular interferon $\beta$-1a therapy initiated during a first demyelinating event in multiple sclerosis. CHAMPS Study Group. N Engl J Med 343:898-904, 2000.

41. CHAMPS Study Group. Baseline MRI characteristics of patients at high risk for multiple sclerosis: results from the CHAMPS trial. Controlled High-Risk Subjects Avonex Multiple Sclerosis Prevention Study. Mult Scler 8:330-338, 2002

42. Kappos L, Patzold U, Dommasch D, Poser S, Haas J, Krauseneck $\mathrm{P}$, et al. Cyclosporine versus azathioprine in the long-term treatment of multiple sclerosis-results of the German multicenter study. Ann Neurol 23:56-63, 1988.

43. Kappos L, Stadt D, Ratzka M, Keil W, Schneiderbanger-Grygier $\mathrm{S}$, Heitzer T, et al. Magnetic resonance imaging in the evaluation of treatment in multiple sclerosis. Neuroradiology 30:299-302, 1988.

44. The Multiple Sclerosis Study Group. Efficacy and toxicity of cyclosporine in chronic progressive multiple sclerosis: a randomized, double-blinded, placebo-controlled clinical trial. Ann Neurol 27:591-605, 1990.

45. Zhao GJ, Li DK, Wolinsky JS, Koopmans RA, Mietlowski W, Redekop WK, et al. Clinical and magnetic resonance imaging changes correlate in a clinical trial monitoring cyclosporine therapy for multiple sclerosis. The MS Study Group. J Neuroimaging 7:1-7, 1997.

46. Paty DW, Li DK. Interferon $\beta$-1b is effective in relapsing-remitting multiple sclerosis. II. MRI analysis results of a multicenter, randomized, double-blind, placebo-controlled trial. UBC MS/ MRI Study Group and the IFNB Multiple Sclerosis Study Group. Neurology 43:662-667, 1993.

47. Filippi M, Horsfield MA, Ader HJ, Barkhof F, Bruzzi P, Evans A, et al. Guidelines for using quantitative measures of brain magnetic resonance imaging abnormalities in monitoring the treatment of multiple sclerosis. Ann Neurol 43:499-506, 1998.

48. Li DK, Paty DW. Magnetic resonance imaging results of the PRISMS trial: a randomized, double-blind, placebo-controlled 
study of interferon- $\beta 1 \mathrm{a}$ in relapsing-remitting multiple sclerosis. Ann Neurol 46:197-206, 1999.

49. Li DK, Zhao GJ, Paty DW; University of British Columbia MS/ MRI Analysis Research Group. Randomized controlled trial of interferon- $\beta$-1a in secondary progressive MS: MRI results. Neurology $56: 1505-1513,2001$.

50. Miller DH, Molyneux PD, Barker GJ, MacManus DG, Moseley IF, Wagner K. Effect of interferon- $\beta 1 \mathrm{~b}$ on magnetic resonance imaging outcomes in secondary progressive multiple sclerosis: results of a European multicenter, randomized, double-blind, placebo-controlled trial. European Study Group on Interferon- $\beta 1 \mathrm{~b}$ in secondary progressive multiple sclerosis. Ann Neurol 46:850 859, 1999.

51. Comi G, Filippi M, Wolinsky JS. European/Canadian multicenter, double-blind, randomized, placebo-controlled study of the effects of glatiramer acetate on magnetic resonance imagingmeasured disease activity and burden in patients with relapsing multiple sclerosis. European/Canadian Glatiramer Acetate Study Group. Ann Neurol 49:290-297, 2001.

52. Molyneux PD, Miller DH, Filippi M, Yousry T, Kappos L, Gasperini $\mathrm{C}$, et al. The use of magnetic resonance imaging in multiple sclerosis treatment trials: power calculations for annual lesion load measurement. J Neurol 247:34-40, 2000.

53. Silver NC, Good CD, Barker GJ, MacManus DG, Thompson AJ, Moseley IF, et al. Sensitivity of contrast enhanced MRI in multiple sclerosis. Effects of gadolinium dose, magnetization transfer contrast and delayed imaging. Brain 120:1149-1161, 1997.

54. Wolansky LJ, Bardini JA, Cook SD, Zimmer AE, Sheffet A, Lee HJ. Triple-dose versus single-dose gadoteridol in multiple sclerosis patients. J Neuroimaging 4:141-145, 1994.

55. Nesbit GM, Forbes GS, Scheithauer BW, Okazaki H, Rodriguez M. Multiple sclerosis: histopathologic and MR and/or CT correlation in 37 cases at biopsy and three cases at autopsy. Radiology 180:467-474, 1991.

56. Katz D, Taubenberger JK, Cannella B, McFarlin DE, Raine CS, McFarland HF. Correlation between magnetic resonance imaging findings and lesion development in chronic, active multiple sclerosis. Ann Neurol 34:661-669, 1993.

57. Bruck W, Bitsch A, Kolenda H, Bruck Y, Stiefel M, Lassmann H. Inflammatory central nervous system demyelination: correlation of magnetic resonance imaging findings with lesion pathology. Ann Neurol 42:783-793, 1997.

58. Kupersmith MJ, Alban T, Zeiffer B, Lefton D. Contrast-enhanced MRI in acute optic neuritis: relationship to visual performance. Brain 125:812-822, 2002.

59. Youl BD, Turano G, Miller DH, Towell AD, MacManus DG, Moore SG, et al. The pathophysiology of acute optic neuritis. An association of gadolinium leakage with clinical and electrophysiological deficits. Brain 114:2437-2450, 1991.

60. McFarland HF, Stone LA, Calabresi PA, Maloni H, Bash CN, Frank JA. MRI studies of multiple sclerosis: implications for the natural history of the disease and for monitoring effectiveness of experimental therapies. Mult Scler 2:198-205, 1996.

61. Kappos L, Moeri D, Radue EW, Schoetzau A, Schweikert K, Barkhof F, et al. Predictive value of gadolinium-enhanced magnetic resonance imaging for relapse rate and changes in disability or impairment in multiple sclerosis: a meta-analysis. Gadolinium MRI Meta-analysis Group. Lancet 353:964-969, 1999.

62. Ebers G, for the PRISMS (Prevention of Relapses and Disability by Interferon $\beta$-1a Subcutaneously in Multiple Sclerosis) Study Group. Randomised double-blind placebo-controlled study of interferon $\beta$-1a in relapsing/remitting multiple sclerosis. Lancet 352:1498-1504, 1998.

63. Miller DH, Khan OA, Sheremata WA, Blumhardt LD, Rice GP, Libonati MA, et al. A controlled trial of natalizumab for relapsing multiple sclerosis. N Engl J Med 348:15-23, 2003.

64. Kappos L, for the European Study Group on interferon $\beta$-1b in secondary progressive MS. Placebo-controlled multicentre randomised trial of interferon $\beta-1 \mathrm{~b}$ in treatment of secondary progressive multiple sclerosis. Lancet 352:1491-1497, 1998.

65. Rice GP, Filippi M, Comi G. Cladribine and progressive MS: clinical and MRI outcomes of a multicenter controlled trial. Cladribine MRI Study Group. Neurology 54:1145-1155, 2000.
66. Sormani MP, Molyneux PD, Gasperini C, Barkhof F, Yousry TA, Miller DH, et al. Statistical power of MRI monitored trials in multiple sclerosis: new data and comparison with previous results. J Neurol Neurosurg Psychiatry 66:465-469, 1999.

67. Sormani MP, Miller DH, Comi G, Barkhof F, Rovaris M, Bruzzi $\mathrm{P}$, et al. Clinical trials of multiple sclerosis monitored with enhanced MRI: new sample size calculations based on large data sets. J Neurol Neurosurg Psychiatry 70:494-499, 2001.

68. Sormani MP, Rovaris M, Bagnato F, Molyneux P, Bruzzi P, Pozzilli C, et al. Sample size estimations for MRI-monitored trials of MS comparing new vs standard treatments. Neurology 57: 1883-1885, 2001.

69. Filippi M, Rovaris M, Capra R, Gasperini C, Yousry TA, Sormani MP, et al. A multi-centre longitudinal study comparing the sensitivity of monthly MRI after standard and triple dose gadolinium-DTPA for monitoring disease activity in multiple sclerosis. Implications for phase II clinical trials. Brain 121:2011-2020, 1998.

70. Rovaris M, Capra R, Martinelli V, Gasperini C, Prandini F, Pozzilli C, et al. Cumulative effect of a weekly low dose of interferon $\beta$ 1a on standard and triple dose contrast-enhanced MRI from multiple sclerosis patients. J Neurol Sci 171:130-134, 1999.

71. Rovaris M, Codella M, Moiola L, Ghezzi A, Zaffaroni M, Mancardi G, et al. Effect of glatiramer acetate on MS lesions enhancing at different gadolinium doses. Neurology 59:1429-1432, 2002.

72. TNF neutralization in MS: results of a randomized, placebocontrolled multicenter study. The Lenercept Multiple Sclerosis Study Group and The University of British Columbia MS/MRI Analysis Group. Neurology 53:457-465, 1999.

73. Bielekova B, Goodwin B, Richert N, Cortese I, Kondo T, Afshar $\mathrm{G}$, et al. Encephalitogenic potential of the myelin basic protein peptide (amino acids 83-99) in multiple sclerosis: results of a phase II clinical trial with an altered peptide ligand. Nat Med 6:1167-1175, 2000.

74. Barkhof F, McGowan JC, van Waesberghe JH, Grossman RI. Hypointense multiple sclerosis lesions on T1-weighted spin echo magnetic resonance images: their contribution in understanding multiple sclerosis evolution. J Neurol Neurosurg Psychiatry 64(Suppl 1):S77-S79, 1998.

75. Rovaris M, Comi G, Rocca MA, Cercignani M, Colombo B, Santuccio G, et al. Relevance of hypointense lesions on fast fluid-attenuated inversion recovery MR images as a marker of disease severity in cases of multiple sclerosis. AJNR Am J Neuroradiol 20:813-820, 1999.

76. Ciccarelli O, Giugni E, Paolillo A, Mainero C, Gasperini C, Bastianello S, et al. Magnetic resonance outcome of new enhancing lesions in patients with relapsing-remitting multiple sclerosis. Eur J Neurol 6:455-459, 1999.

77. Bitsch A, Kuhlmann T, Stadelmann C, Lassmann H, Lucchinetti C, Brueck W. A longitudinal MRI study of histopathologically defined hypointense multiple sclerosis lesions. Ann Neurol 49: 793-796, 2001

78. Leist TP, Gobbini MI, Frank JA, McFarland HF. Enhancing magnetic resonance imaging lesions and cerebral atrophy in patients with relapsing multiple sclerosis. Arch Neurol 58:57-60, 2001.

79. van Walderveen MA, Kamphorst W, Scheltens P, van Waesberghe JH, Ravid R, Valk J, et al. Histopathologic correlate of hypointense lesions on T1-weighted spin- echo MRI in multiple sclerosis. Neurology 50:1282-1288, 1998.

80. Meier DS, Weiner HL, Khoury SJ, Guttmann CR. Magnetic resonance imaging surrogates of multiple sclerosis pathology and their relationship to central nervous system atrophy. J Neuroimaging 14(Suppl 3):46S-53S, 2004.

81. van Walderveen MA, Barkhof F, Pouwels PJ, van Schijndel RA, Polman CH, Castelijns JA. Neuronal damage in T1-hypointense multiple sclerosis lesions demonstrated in vivo using proton magnetic resonance spectroscopy. Ann Neurol 46:79-87, 1999.

82. Pike GB, de Stefano N, Narayanan S, Francis GS, Antel JP, Arnold DL. Combined magnetization transfer and proton spec- 
troscopic imaging in the assessment of pathologic brain lesions in multiple sclerosis. AJNR Am J Neuroradiol 20:829-837, 1999.

83. Li BS, Regal J, Soher BJ, Mannon LJ, Grossman RI, Gonen O. Brain metabolite profiles of T1-hypointense lesions in relapsingremitting multiple sclerosis. AJNR Am J Neuroradiol 24:68-74, 2003.

84. Truyen $\mathrm{L}$, van Waesberghe JH, van Walderveen MA, van Oosten BW, Polman CH, Hommes OR, et al. Accumulation of hypointense lesions ("black holes") on T1 spin-echo MRI correlates with disease progression in multiple sclerosis. Neurology 47:14691476, 1996.

85. Enzinger C, Ropele S, Smith S, Strasser-Fuchs S, Poltrum B, Schmidt $\mathrm{H}$, et al. Accelerated evolution of brain atrophy and "black holes" in MS patients with APOE-e4. Ann Neurol 55:563569, 2004.

86. Wolinsky JS, Narayana PA, He R. Overview of treatment trials: early baseline clinical and MRI data of the PROMiSe trial. Primary progressive multiple sclerosis. Milano: Springer Italia, pp 47-61, 2002.

87. Gasperini C, Pozzilli C, Bastianello S, Giugni E, Horsfield MA, Koudriavtseva $\mathrm{T}$, et al. Interferon- $\beta$ - $1 \mathrm{a}$ in relapsing-remitting multiple sclerosis: effect on hypointense lesion volume on T1 weighted images. J Neurol Neurosurg Psychiatry 67:579-584, 1999.

88. Simon JH, Lull J, Jacobs LD, Rudick RA, Cookfair DL, Herndon $\mathrm{RM}$, et al. A longitudinal study of $\mathrm{T} 1$ hypointense lesions in relapsing MS: MSCRG trial of interferon $\beta$-1a. Multiple Sclerosis Collaborative Research Group. Neurology 55:185-192, 2000.

89. Wolinsky JS, Comi G, Filippi M, Ladkani D, Kadosh S, Shifroni G. Copaxone's effect on MRI-monitored disease in relapsing MS is reproducible and sustained. Neurology 59:1284-1286, 2002.

90. Rocca MA, Mastronardo G, Rodegher M, Comi G, Filippi M. Long-term changes of magnetization transfer-derived measures from patients with relapsing-remitting and secondary progressive multiple sclerosis. AJNR Am J Neuroradiol 20:821-827, 1999.

91. Barkhof F, Van Waesberghe JH, Filippi M, Yuosry T, Miller DH, Hahn D, et al. T1 hypointense lesions in secondary progressive multiple sclerosis: effect of interferon $\beta$-1b treatment. Brain 124: 1396-1402, 2001.

92. Filippi M, Rovaris M, Rice GP, Sormani MP, Iannucci G, Giacomotti L, et al. The effect of cladribine on T(1) 'black hole' changes in progressive MS. J Neurol Sci 176:42-44, 2000.

93. Paolillo A, Coles AJ, Molyneux PD, Gawne-Cain M, MacManus D, Barker GJ, et al. Quantitative MRI in patients with secondary progressive MS treated with monoclonal antibody Campath ${ }^{1} \mathrm{H}$. Neurology 53:751-757, 1999.

94. Dalton CM, Miszkiel KA, Barker GJ, MacManus DG, Pepple TI, Panzara M, et al. Effect of natalizumab on conversion of gadolinium enhancing lesions to T1 hypointense lesions in relapsing multiple sclerosis. J Neurol 251:407-413, 2004.

95. Lin A, Ross BD, Harris K, Wong W. Efficacy of proton magnetic resonance spectroscopy in neurological diagnosis and neurotherapeutic decision making. NeuroRx 2:197-214, 2005.

96. Narayana PA, Wolinsky JS, Jackson EF, McCarthy M. Proton MR spectroscopy of gadolinium-enhanced multiple sclerosis plaques. J Magn Reson Imaging 2:263-270, 1992.

97. Mader I, Seeger U, Weissert R, Klose U, Naegele T, Melms A, et al. Proton MR spectroscopy with metabolite-nulling reveals elevated macromolecules in acute multiple sclerosis. Brain 124:953961, 2001.

98. Helms G. Volume correction for edema in single-volume proton MR spectroscopy of contrast-enhancing multiple sclerosis lesions. Magn Reson Med 46:256-263, 2001.

99. Bitsch A, Bruhn H, Vougioukas V, Stringaris A, Lassmann H, Frahm J, et al. Inflammatory CNS demyelination: histopathologic correlation with in vivo quantitative proton MR spectroscopy. AJNR: Am J Neuroradiol 20:1619-1627, 1999.

100. Brex PA, Parker GJ, Leary SM, Molyneux PD, Barker GJ, Davie $\mathrm{CA}$, et al. Lesion heterogeneity in multiple sclerosis: a study of the relations between appearances on T1 weighted images, T1 relaxation times, and metabolite concentrations. J Neurol Neurosurg Psychiatry 68:627-632, 2000.

101. Bjartmar C, Trapp BD. Axonal and neuronal degeneration in multiple sclerosis: mechanisms and functional consequences. Curr Opin Neurol 14:271-278, 2001.

102. Kapeller P, McLean MA, Griffin CM, Chard D, Parker GJ, Barker GJ, et al. Preliminary evidence for neuronal damage in cortical grey matter and normal appearing white matter in short duration relapsing-remitting multiple sclerosis: a quantitative MR spectroscopic imaging study. J Neurol 248:131-138, 2001.

103. Davie CA, Barker GJ, Thompson AJ, Tofts PS, McDonald WI, Miller DH. ${ }^{1} \mathrm{H}$ magnetic resonance spectroscopy of chronic cerebral white matter lesions and normal appearing white matter in multiple sclerosis. J Neurol Neurosurg Psychiatry 63:736-742, 1997.

104. Fu L, Matthews PM, De Stefano N, Worsley KJ, Narayanan S, Francis GS, et al. Imaging axonal damage of normal-appearing white matter in multiple sclerosis. Brain 121:103-113, 1998.

105. De Stefano N, Narayanan S, Francis GS, Arnaoutelis R, Tartaglia MC, Antel JP, et al. Evidence of axonal damage in the early stages of multiple sclerosis and its relevance to disability. Arch Neurol 58:65-70, 2001.

106. Gonen O, Catalaa I, Babb JS, Ge Y, Mannon LJ, Kolson DL, et al. Total brain N-acetylaspartate: a new measure of disease load in MS. Neurology 54:15-19, 2000.

107. Brex PA, Gomez-Anson B, Parker GJ, Molyneux PD, Miszkiel KA, Barker GJ, et al. Proton MR spectroscopy in clinically isolated syndromes suggestive of multiple sclerosis. J Neurol Sci 166:16-22, 1999.

108. Cucurella MG, Rovira A, Rio J, Pedraza S, Tintore MM, Montalban X, et al. Proton magnetic resonance spectroscopy in primary and secondary progressive multiple sclerosis. NMR Biomed 13:57-63, 2000.

109. Bjartmar C, Battistuta J, Terada N, Dupree E, Trapp BD. Nacetylaspartate is an axon-specific marker of mature white matter in vivo: a biochemical and immunohistochemical study on the rat optic nerve. Ann Neurol 51:51-58, 2002.

110. Kidd D, Barkhof F, McConnell R, Algra PR, Allen IV, Revesz T. Cortical lesions in multiple sclerosis. Brain 122:17-26, 1999.

111. Bakshi R, Ariyaratana S, Benedict RHB, Jacobs L. Fluid-attenuated inversion recovery magnetic resonance imaging detects cortical and juxtacortical multiple sclerosis lesions. Arch Neurol 58:742-748, 2001.

112. Inglese M, Liu S, Babb JS, Mannon LJ, Grossman RI, Gonen O. Three-dimensional proton spectroscopy of deep gray matter nuclei in relapsing-remitting MS. Neurology 63:170-172, 2004.

113. Bermel RA, Innus MD, Tjoa CW, Bakshi R. Selective caudate atrophy in multiple sclerosis: a 3D MRI parcellation study. $\mathrm{Neu}$ roreport 14:335-339, 2003.

114. Tourbah A, Stievenart JL, Abanou A, Fontaine B, Cabanis EA, Lyon-Caen O. Correlating multiple MRI parameters with clinical features: an attempt to define a new strategy in multiple sclerosis. Neuroradiology 43:712-720, 2001.

115. Suhy J, Rooney WD, Goodkin DE, Capizzano AA, Soher BJ, Maudsley AA, et al. ${ }^{1} \mathrm{H}$ MRSI comparison of white matter and lesions in primary progressive and relapsing-remitting MS. Mult Scler 6:148-155, 2000.

116. Narayana PA, Wolinsky JS, Rao SB, He R, Mehta M. Multicentre proton magnetic resonance spectroscopy imaging of primary progressive multiple sclerosis. Mult Scler 10(Suppl 1):S73-S78, 2004.

117. Pan JW, Krupp LB, Elkins LE, Coyle PK. Cognitive dysfunction lateralizes with NAA in multiple sclerosis. Appl Neuropsychol $8: 155-160,2001$.

118. Reddy H, Narayanan S, Arnoutelis R, Jenkinson M, Antel J, Matthews PM, et al. Evidence for adaptive functional changes in the cerebral cortex with axonal injury from multiple sclerosis. Brain 123:2314-2320, 2000.

119. Arnold DL, Wolinsky JS, Matthews PM, Falini A. The use of magnetic resonance spectroscopy in the evaluation of the natural history of multiple sclerosis. J Neurol Neurosurg Psychiatry 649(Suppl 1):S94-101, 1998.

120. Narayanan S, De Stefano N, Francis GS, Arnaoutelis R, Caramanos Z, Collins DL, et al. Axonal metabolic recovery in multiple sclerosis patients treated with interferon $\beta$-1b. J Neurol 248:979986, 2001. 
121. Sarchielli P, Presciutti O, Tarducci R, Gobbi G, Alberti A, Pelliccioli GP, et al. ${ }^{1} \mathrm{H}-\mathrm{MRS}$ in patients with multiple sclerosis undergoing treatment with interferon $\beta$-1a: results of a preliminary study. J Neurol Neurosurg Psychiatry 64:204-212, 1998.

122. Schubert F, Seifert F, Elster C, Link A, Walzel M, Mientus S, et al. Serial ${ }^{1} \mathrm{H}-\mathrm{MRS}$ in relapsing-remitting multiple sclerosis: effects of interferon- $\beta$ therapy on absolute metabolite concentrations. MAGMA 14:213-222, 2002.

123. Parry A, Corkill R, Blamire AM, Palace J, Narayanan S, Arnold $\mathrm{D}$, et al. $\beta$-Interferon treatment does not always slow the progression of axonal injury in multiple sclerosis. J Neurol 250:171-178, 2003.

124. Inglese M, Ge Y, Filippi M, Falini A, Grossman RI, Gonen O. Indirect evidence for early widespread gray matter involvement in relapsing-remitting multiple sclerosis. Neuroimage 21:1825-1829, 2004.

125. Horsfield MA, Barker GJ, Barkhof F, Miller DH, Thompson AJ, Filippi M. Guidelines for using quantitative magnetization transfer magnetic resonance imaging for monitoring treatment of multiple sclerosis. J Magn Reson Imaging 17:389-397, 2003.

126. Filippi M, Rocca MA. Magnetization transfer magnetic resonance imaging in the assessment of neurological diseases. J Neuroimaging 14:303-313, 2004.

127. Dousset V, Grossman RI, Ramer KN, Schnall MD, Young LH, Gonzalez-Scarano F, et al. Experimental allergic encephalomyelitis and multiple sclerosis: lesion characterization with magnetization transfer imaging. Radiology 182:483-491, 1992.

128. van Buchem MA, McGowan JC, Kolson DL, Polansky M, Grossman RI. Quantitative volumetric magnetization transfer analysis in multiple sclerosis: estimation of macroscopic and microscopic disease burden. Magn Reson Med 36:632-636, 1996.

129. van Waesberghe JH, van Walderveen MA, Castelijns JA, Scheltens P, Lycklama a Nijeholt GJ et al. Patterns of lesion development in multiple sclerosis: longitudinal observations with T1weighted spin-echo and magnetization transfer MR. AJNR Am J Neuroradiol 19:675-683, 1998.

130. Lai HM, Davie CA, Gass A, Barker GJ, Webb S, Tofts PS, et al. Serial magnetisation transfer ratios in gadolinium-enhancing lesions in multiple sclerosis. J Neurol 244:308-311, 1997.

131. Filippi M, Rocca MA, Martino G, Horsfield MA, Comi G. Magnetization transfer changes in the normal appearing white matter precede the appearance of enhancing lesions in patients with multiple sclerosis. Ann Neurol 43:809-814, 1998.

132. Goodkin DE, Rooney WD, Sloan R, Bacchetti P, Gee L, Vermathen M, et al. A serial study of new MS lesions and the white matter from which they arise. Neurology 51:1689-1697, 1998.

133. Silver NC, Lai M, Symms MR, Barker GJ, McDonald WI, Miller DH. Serial magnetization transfer imaging to characterize the early evolution of new MS lesions. Neurology 51:758-764, 1998.

134. Pike GB, De Stefano N, Narayanan S, Worsley KJ, Pelletier D, Francis GS, et al. Multiple sclerosis: magnetization transfer MR imaging of white matter before lesion appearance on T2-weighted images. Radiology 215:824-830, 2000.

135. Fazekas F, Ropele S, Enzinger C, Seifert T, Strasser-Fuchs S. Quantitative magnetization transfer imaging of pre-lesional white-matter changes in multiple sclerosis. Mult Scler 8:479484, 2002.

136. Miller DH, Thompson AJ, Filippi M. Magnetic resonance studies of abnormalities in the normal appearing white matter and grey matter in multiple sclerosis. J Neurol 250:1407-1419, 2003.

137. Ostuni JL, Richert ND, Lewis BK, Frank JA. Characterization of differences between multiple sclerosis and normal brain: a global magnetization transfer application. AJNR Am J Neuroradiol 20: 501-507, 1999.

138. Filippi M, Campi A, Dousset V, Baratti C, Martinelli V, Canal N, et al. A magnetization transfer imaging study of normal-appearing white matter in multiple sclerosis. Neurology 45:478-482, 1995.

139. Audoin B, Ranjeva JP, Duong MV, Ibarrola D, Malikova I, Confort-Gouny S, et al. Voxel-based analysis of MTR images: a method to locate gray matter abnormalities in patients at the earliest stage of multiple sclerosis. J Magn Reson Imaging 20: 765-771, 2004.
140. Lycklama a Nijeholt GJ, Castelijns JA, Lazeron RH, van Waesberghe $\mathrm{JH}$, Polman $\mathrm{CH}$, Uitdehaag BM, et al. Magnetization transfer ratio of the spinal cord in multiple sclerosis: relationship to atrophy and neurologic disability. J Neuroimaging 10:67-72, 2000.

141. Thorpe JW, Barker GJ, Jones SJ, Moseley I, Losseff N, MacManus DG, et al. Magnetisation transfer ratios and transverse magnetisation decay curves in optic neuritis: correlation with clinical findings and electrophysiology. J Neurol Neurosurg Psychiatry 59:487-492, 1995.

142. Filippi M, Iannucci G, Tortorella C, Minicucci L, Horsfield MA, Colombo B, et al. Comparison of MS clinical phenotypes using conventional and magnetization transfer MRI. Neurology 52:588-594, 1999.

143. Rovaris M, Agosta F, Sormani MP, Inglese M, Martinelli V, Comi G, et al. Conventional and magnetization transfer MRI predictors of clinical multiple sclerosis evolution: a medium-term follow-up study. Brain 126:2323-2332, 2003.

144. Santos AC, Narayanan S, de Stefano N, Tartaglia MC, Francis SJ, Arnaoutelis R, et al. Magnetization transfer can predict clinical evolution in patients with multiple sclerosis. J Neurol 249:662668, 2002.

145. Patel UJ, Grossman RI, Phillips MD, Udupa JK, McGowan JC, Miki Y, et al. Serial analysis of magnetization-transfer histograms and Expanded Disability Status Scale scores in patients with relapsing-remitting multiple sclerosis. AJNR Am J Neuroradiol 20:1946-1950, 1999.

146. Cox D, Pelletier D, Genain C, Majumdar S, Lu Y, Nelson S, Mohr DC. The unique impact of changes in normal appearing brain tissue on cognitive dysfunction in secondary progressive multiple sclerosis patients. Mult Scler 10:626-629, 2004.

147. Zivadinov R, De Masi R, Nasuelli D, Bragadin LM, Ukmar M, Pozzi-Mucelli RS, et al. MRI techniques and cognitive impairment in the early phase of relapsing-remitting multiple sclerosis. Neuroradiology 43:272-278, 2001.

148. Richert ND, Frank JA. Magnetization transfer imaging to monitor clinical trials in multiple sclerosis. Neurology 53(5 Suppl 3):S29S32, 1999.

149. Filippi M. Magnetization transfer MRI in multiple sclerosis and other central nervous system disorders. Eur J Neurol 10:3-10, 2003.

150. Richert ND, Ostuni JL, Bash CN, Duyn JH, McFarland HF, Frank JA. Serial whole-brain magnetization transfer imaging in patients with relapsing-remitting multiple sclerosis at baseline and during treatment with interferon $\beta$-1b. AJNR Am J Neuroradiol 19: 1705-1713, 1998.

151. Filippi M, Inglese M, Rovaris M, Sormani MP, Horsfield P, Iannucci PG, et al. Magnetization transfer imaging to monitor the evolution of MS: a 1-year follow-up study. Neurology 55:940 946, 2000.

152. Inglese M, van Waesberghe JH, Rovaris M, Beckmann K, Barkhof $\mathrm{F}$, Hahn $\mathrm{D}$, et al. The effect of interferon $\beta$-1b on quantities derived from MT MRI in secondary progressive MS. Neurology 60:853-860, 2003.

153. Filippi M, Rocca MA, Pagani E, Iannucci G, Sormani MP, Fazekas F, et al. European study on intravenous immunoglobulin in multiple sclerosis: results of magnetization transfer magnetic resonance imaging analysis. Arch Neurol 61:1409-1412, 2004.

154. Kita M, Goodkin DE, Bacchetti P, Waubant E, Nelson SJ, Majumdar S. Magnetization transfer ratio in new MS lesions before and during therapy with IFN $\beta$-1a. Neurology 54:1741-1745, 2000.

155. Frank JA, Richert N, Lewis B, Bash C, Howard T, Civil R, et al. A pilot study of recombinant insulin-like growth factor-1 in seven multiple sclerosis patients. Mult Scler 8:24-29, 2002.

156. Miller DH, Barkhof F, Frank JA, Parker GJ, Thompson AJ. Measurement of atrophy in multiple sclerosis: pathological basis, methodological aspects and clinical relevance. Brain 125:1676$1695,2002$.

157. Zivadinov R, Bakshi R. Role of MRI in multiple sclerosis II: brain and spinal cord atrophy. Front Biosci 9:647-664, 2004.

158. Simon JH. From enhancing lesions to brain atrophy in relapsing MS. J Neuroimmunol 98:7-15, 1999. 
159. Minagar A, Toledo EG, Alexander JS, Kelley RE. Pathogenesis of brain and spinal cord atrophy in multiple sclerosis. J Neuroimaging 14(3 Suppl):5S-10S, 2004.

160. Lassmann H. Mechanisms of demyelination and tissue damage in multiple sclerosis. Acta Neurol Belg 99:6-10, 1999.

161. Cifelli A, Arridge M, Jezzard P, Esiri MM, Palace J, Matthews PM. Thalamic neurodegeneration in multiple sclerosis. Ann Neurol 52:650-653, 2002.

162. Filippi M, Rovaris M, Inglese M, Barkhof F, De Stefano N, Smith $\mathrm{S}$, et al. Interferon $\beta-1 \mathrm{a}$ for brain tissue loss in patients at presentation with syndromes suggestive of multiple sclerosis: a randomised, double-blind, placebo-controlled trial. Lancet 364:1489-1496, 2004.

163. Pelletier D, Garrison K, Henry R. Measurement of whole-brain atrophy in multiple sclerosis. J Neuroimaging 14(3 Suppl):11S19S, 2004.

164. Simon JH. Linear and regional measures of brain atrophy in multiple sclerosis. In: Brain and spinal cord atrophy in multiple sclerosis (Zivadinov R, Bakshi R, eds). Hauppauge: Nova Science, pp 15-27, 2004.

165. Lin X, Tench CR, Evangelou N, Jaspan T, Constantinescu CS. Measurement of spinal cord atrophy in multiple sclerosis. $\mathrm{J} \mathrm{Neu-}$ roimaging 14(3 Suppl):20S-26S, 2004.

166. Benedict RH, Carone DA, Bakshi R. Correlating brain atrophy with cognitive dysfunction, mood disturbances, and personality disorder in multiple sclerosis. J Neuroimaging 14(3 Suppl):36S45S, 2004.

167. Zivadinov R, Bakshi R. Central nervous system atrophy and clinical status in multiple sclerosis. J Neuroimaging 14(Suppl): 27S-35S, 2004.

168. Losseff NA, Wang L, Lai HM, Yoo DS, Gawne-Cain ML, McDonald WI, et al. Progressive cerebral atrophy in multiple sclerosis. A serial MRI study. Brain 119:2009-2019, 1996.

169. Dastidar P, Heinonen T, Lehtimaki T, Ukkonen M, Peltola J, Erila T, Laasonen E, Elovaara I. Volumes of brain atrophy and plaques correlated with neurological disability in secondary progressive multiple sclerosis. J Neurol Sci 165:36-42, 1999.

170. Bermel RA, Sharma J, Tjoa CW, Puli SR, Bakshi R. A semiautomated measure of whole-brain atrophy in multiple sclerosis. J Neurol Sci 208:57-65, 2003.

171. Fisher E, Rudick RA, Simon JH, Cutter G, Baier M, Lee JC, et al. Eight-year follow-up study of brain atrophy in patients with MS. Neurology 59:1412-1420, 2002.

172. Kidd D, Thorpe JW, Kendall BE, Barker GJ, Miller DH, McDonald WI, et al. MRI dynamics of brain and spinal cord in progressive multiple sclerosis. J Neurol Neurosurg Psychiatry 60:15-19, 1996.

173. Stevenson VL, Miller DH, Leary SM, Rovaris M, Barkhof F, Brochet B, et al. One year follow up study of primary and transitional progressive multiple sclerosis. J Neurol Neurosurg Psychiatry 68:713-718, 2000.

174. Ingle GT, Stevenson VL, Miller DH, Thompson AJ. Primary progressive multiple sclerosis: a 5-year clinical and MR study. Brain 126:2528-2536, 2003.

175. Lin X, Tench CR, Turner B, Blumhardt LD, Constantinescu CS. Spinal cord atrophy and disability in multiple sclerosis over four years: application of a reproducible automated technique in monitoring disease progression in a cohort of the interferon $\beta$-1a (Rebif) treatment trial. J Neurol Neurosurg Psychiatry 74:10901094, 2003.

176. Rao SM, Glatt S, Hammeke TA, McQuillen MP, Khatri BO, Rhodes AM, et al. Chronic progressive multiple sclerosis. Relationship between cerebral ventricular size and neuropsychological impairment. Arch Neurol 42:678-682, 1985.

177. Tsolaki M, Drevelegas A, Karachristianou S, Kapinas K, Divanoglou D, Routsonis K. Correlation of dementia, neuropsychological and MRI findings in multiple sclerosis. Dementia 5:48-52, 1994.

178. Bermel RA, Bakshi R, Tjoa C, Puli SR, Jacobs L. Bicaudate ratio as a magnetic resonance imaging marker of brain atrophy in multiple sclerosis. Arch Neurol 59:275-280, 2002.

179. Christodoulou C, Krupp LB, Liang Z, Huang W, Melville P, Roque $\mathrm{C}$, et al. Cognitive performance and MR markers of cere- bral injury in cognitively impaired MS patients. Neurology 60: 1793-1798, 2003.

180. Hohol MJ, Guttmann CR, Orav J, Mackin GA, Kikinis R, Khoury $\mathrm{SJ}$, et al. Serial neuropsychological assessment and magnetic resonance imaging analysis in multiple sclerosis. Arch Neurol 54:1018-1025, 1997.

181. Zivadinov R, Sepcic J, Nasuelli D, De Masi R, Bragadin LM, Tommasi MA, et al. A longitudinal study of brain atrophy and cognitive disturbances in the early phase of relapsing-remitting multiple sclerosis. J Neurol Neurosurg Psychiatry 70:773-780, 2001.

182. Benedict RHB, Weinstock-Guttman B, Fishman I, Sharma J, Tjoa $\mathrm{CW}$, Bakshi R. Prediction of neuropsychological impairment in multiple sclerosis: comparison of conventional magnetic resonance imaging measures of atrophy and lesion burden. Arch Neurol 61:226-230, 2004.

183. Amato M P, Bartolozzi ML, Zipoli V, Portaccio E, Mortilla M, Guidi L, et al. Neocortical volume decrease in relapsing-remitting MS patients with mild cognitive impairment. Neurology 63:8993, 2004.

184. Benedict RHB, Sanfilipo M, Weinstock-Guttman B, Sharma J, Tjoa C, Bakshi R. The relationship of gray, white and total brain parenchymal fraction with cognitive performance in multiple sclerosis. Neurology 62(Suppl 5):A289, 2004.

185. Benedict RHB, Zivadinov R, Carone DA, Weinstock-Guttman B, Gaines J, Bakshi R. Temporal lobe atrophy predicts memory impairment in multiple sclerosis. AJNR Am J Neuroradiol, in press.

186. Rudick RA. Impact of disease-modifying therapies on brain and spinal cord atrophy in multiple sclerosis. J Neuroimaging 14(3 Suppl):54S-64S, 2004.

187. Rovaris M, Filippi M. Treatment effects on MRI measures of central nervous system atrophy in multiple sclerosis. In: Brain and spinal cord atrophy in multiple sclerosis (Zivadinov R, Bakshi R, eds), pp 175-190. Hauppauge: Nova Science, 2004.

188. Rudick RA, Fisher E, Lee JC, Simon J, Jacobs L. Use of the brain parenchymal fraction to measure whole brain atrophy in relapsing-remitting MS. Multiple Sclerosis Collaborative Research Group. Neurology 53:1698-1704, 1999.

189. Jones CK, Riddehough A, Li DKB, Zhao G, Paty DW, PRISMS Study Group, et al. MRI cerebral atrophy in relapsing-remitting MS: results from the PRISMS trial. Neurology 56(Suppl 3):A379, 2001.

190. Molyneux PD, Kappos L, Polman C, Pozzilli C, Barkhof F, Filippi M, et al. The effect of interferon $\beta-1 \mathrm{~b}$ treatment on MRI measures of cerebral atrophy in secondary progressive multiple sclerosis. European Study Group on Interferon $\beta-1 \mathrm{~b}$ in secondary progressive multiple sclerosis. Brain 123:2256-2263, 2000.

191. Frank JA, Richert N, Bash C, Stone L, Calabresi PA, Lewis B, Stone R, Howard T, McFarland HF. Interferon- $\beta-1 \mathrm{~b}$ slows progression of atrophy in RRMS: three-year follow-up in NAb- and $\mathrm{NAb}+$ patients. Neurology 62:719-725, 2004.

192. Ge Y, Grossman RI, Udupa JK, Fulton J, Constantinescu CS, Gonzales-Scarano F, et al. Glatiramer acetate (Copaxone) treatment in relapsing-remitting MS: quantitative MR assessment. Neurology 54:813-817, 2000.

193. Wolinsky JS, Narayana PA, Johnson KP; Multiple Sclerosis Study Group and the MRI Analysis Center. United States openlabel glatiramer acetate extension trial for relapsing multiple sclerosis: MRI and clinical correlates. Mult Scler 7:33-41, 2001.

194. Rovaris M, Comi G, Rocca MA, Wolinsky JS, Filippi M; European/Canadian Glatiramer Acetate Study Group. Short-term brain volume change in relapsing-remitting multiple sclerosis: effect of glatiramer acetate and implications. Brain 124:1803-1812, 2001

195. Sormani MP, Rovaris M, Valsasina P, Wolinsky JS, Comi G, Filippi M. Measurement error of two different techniques for brain atrophy assessment in multiple sclerosis. Neurology 62: 1432-1434, 2004.

196. Zivadinov R, Rudick RA, De Masi R, Nasuelli D, Ukmar M, PozziMucelli RS, et al. Effects of IV methylprednisolone on brain atrophy in relapsing-remitting MS. Neurology 7:1239-1247, 2001.

197. Gasperini C. Whole-brain atrophy measurement and short-term brain volume changes. In: Brain and spinal cord atrophy in mul- 
tiple sclerosis (Zivadinov R, Bakshi R, eds). Hauppauge: Nova Science, pp 29-38, 2004.

198. Quint DJ. Hyperintense disks on T1-weighted MR images: are they important? Radiology 195:325-326, 1995.

199. Powell T, Sussman JG, Davies-Jones GA. MR imaging in acute multiple sclerosis: ringlike appearance in plaques suggesting the presence of paramagnetic free radicals. AJNR Am J Neuroradiol 13:1544-1546, 1992.

200. Terada H, Barkovich AJ, Edwards MS, Ciricillo SM. Evolution of high-intensity basal ganglia lesions on T1-weighted MR in neurofibromatosis type 1. AJNR Am J Neuroradiol 17:755-760, 1996.

201. Bakshi R, Suri S, Benedict RHB, Weinstock-Guttman B, Bermel $\mathrm{RA}$, Tjoa CW, et al. Bright lesions in the brain on non-contrast T1-weighted MRI scans (T1 shortening) in multiple sclerosis. Neurology 58(Suppl 3):A208-A209, 2002.

202. Guttmann CRG, Ahn SS, Hsu L, Kikinis R, Jolesz FA. The evolution of multiple sclerosis lesions on serial MR. AJNR Am J Neuroradiol 16:1481-1491, 1995.

203. Drayer BP, Burger P, Hurwitz B, Dawson D, Cain J, Leong J, et al. Magnetic resonance imaging in multiple sclerosis: decreased signal in thalamus and putamen. Ann Neurol 22:546-550, 1987.

204. Bakshi R, Shaikh ZA, Janardhan V. MRI T2 shortening ('black $\mathrm{T} 2^{\prime}$ ) in multiple sclerosis: frequency, location, and clinical correlation. Neuroreport 11:15-21, 2000.

205. Bakshi R, Benedict RH, Bermel RA, Caruthers SD, Puli SR, Tjoa $\mathrm{CW}$, et al. T2 hypointensity in the deep gray matter of patients with multiple sclerosis: a quantitative magnetic resonance imaging study. Arch Neurol 59:62-68, 2002.

206. Bakshi R, Dmochowski J, Shaikh ZA, Jacobs L. Gray matter T2 hypointensity is related to plaques and atrophy in the brains of multiple sclerosis patients. J Neurol Sci 185:19-26, 2001.

207. Bermel RA, Puli SR, Rudick RA, Weinstock-Guttman B, Fisher E, Munschauer FE, Bakshi R. Gray matter MRI T2 hypointensity predicts longitudinal brain atrophy in MS. Arch Neurol, in press.

208. Schenck JF, Zimmerman EA. High-field magnetic resonance imaging of brain iron: birth of a biomarker? NMR Biomed 17:433445, 2004.

209. Gutteridge JMC. Iron and oxygen radicals in brain. Ann Neurol 32:16-21, 1992.

210. Levine SM, Chakrabarty A. The role of iron in the pathogenesis of experimental allergic encephalomyelitis and multiple sclerosis. Ann NY Acad Sci 1012:252-266, 2004.

211. Weilbach FX, Chan A, Toyka KV, Gold R. The cardioprotector dexrazoxane augments therapeutic efficacy of mitoxantrone in experimental autoimmune encephalomyelitis. Clin Exp Immunol 135:49-55, 2004.

212. Bammer R, Skare S, Newbould R, Liu C, Thijs V, Ropele S, Clayton DB, Krueger G, Moseley ME, Glover GH. Foundations of advanced magnetic resonance imaging. NeuroRx 2:167-196, 2005.

213. Filippi M, Inglese M. Overview of diffusion-weighted magnetic resonance studies in multiple sclerosis. J Neurol Sci 186:S37S43, 2001

214. Bammer R, Fazekas F. Diffusion imaging in multiple sclerosis. Neuroimaging Clin N Am 12:71-106, 2002.

215. Droogan AG, Clark CA, Werring DJ, Barker GJ, McDonald WI, Miller DH. Comparison of multiple sclerosis clinical subgroups using navigated spin echo diffusion-weighted imaging. Magn Reson Imaging 17:653-661, 1999.

216. Horsfield MA, Lai M, Webb SL, Barker GJ, Tofts PS, Turner R, et al. Apparent diffusion coefficients in benign and secondary progressive multiple sclerosis by nuclear magnetic resonance. Magn Reson Med 36:393-400, 1996.

217. Bammer R, Augustin M, Strasser-Fuchs S, Seifert T, Kapeller P, Stollberger R, et al. Magnetic resonance diffusion tensor imaging for characterizing diffuse and focal white matter abnormalities in multiple sclerosis. Magn Reson Med 44:583-591, 2000.

218. Werring DJ, Brassat D, Droogan AG, Clark CA, Symms MR, Barker GJ, et al. The pathogenesis of lesions and normal-appearing white matter changes in multiple sclerosis: a serial diffusion MRI study. Brain 123:1667-1676, 2000.
219. Guo AC, MacFall JR, Provenzale JM. Multiple sclerosis: diffusion tensor MR imaging for evaluation of normal-appearing white matter. Radiology 222:729-736, 2002.

220. Roychowdhury S, Maldjian JA, Grossman RI. Multiple sclerosis: comparison of trace apparent diffusion coefficients with MR enhancement pattern of lesions. AJNR Am J Neuroradiol 21:869$874,2000$.

221. Ciccarelli O, Werring DJ, Wheeler-Kingshott CA, Barker GJ, Parker GJ, Thompson AJ, et al. Investigation of MS normalappearing brain using diffusion tensor MRI with clinical correlations. Neurology 56:926-933, 2001.

222. Rocca MA, Cercignani M, Iannucci G, Comi G, Filippi M. Weekly diffusion-weighted imaging of normal-appearing white matter in MS. Neurology 55:882-884, 2000.

223. Coombs BD, Best A, Brown MS, Miller DE, Corboy J, Baier M, et al. Multiple sclerosis pathology in the normal and abnormal appearing white matter of the corpus callosum by diffusion tensor imaging. Mult Scler 10:392-397, 2004.

224. Cassol E, Ranjeva JP, Ibarrola D, Mekies C, Manelfe C, Clanet $\mathrm{M}$, et al. Diffusion tensor imaging in multiple sclerosis: a tool for monitoring changes in normal-appearing white matter. Mult Scler 10:188-196, 2004.

225. Schmierer K, Altmann DR, Kassim N, Kitzler H, Kerskens CM, Doege CA, et al. A. Progressive change in primary progressive multiple sclerosis normal-appearing white matter: a serial diffusion magnetic resonance imaging study. Mult Scler 10:182-187, 2004.

226. Fabiano AJ, Sharma J, Weinstock-Guttman B, Benedict RH, Zivadinov $R$, Bakshi $R$. Thalamic involvement in multiple sclerosis: a diffusion-weighted magnetic resonance imaging study. $\mathrm{J} \mathrm{Neu}$ roimaging 13:307-314, 2003.

227. Rovaris M, Iannucci G, Falautano M, Possa F, Martinelli V, Comi $\mathrm{G}$, et al. Cognitive dysfunction in patients with mildly disabling relapsing-remitting multiple sclerosis: an exploratory study with diffusion tensor MR imaging. J Neurol Sci 195:103-109, 2002.

228. Wilson M, Tench CR, Morgan PS, Blumhardt LD. Pyramidal tract mapping by diffusion tensor magnetic resonance imaging in multiple sclerosis: improving correlations with disability. $\mathrm{J} \mathrm{Neu}$ rol Neurosurg Psychiatry 74:203-207, 2003.

229. Caramia F, Pantano P, Di Legge S, Piattella MC, Lenzi D, Paolillo A, et al. A longitudinal study of MR diffusion changes in NAWM of patients with early multiple sclerosis. Magn Res Imag 20:383-388, 2002.

230. Cercignani M, Bozzali M, Iannucci G, Comi G, Filippi M. Intravoxel and inter-voxel coherence in patients with multiple sclerosis assessed using diffusion tensor MRI. J Neurology 249:875883, 2002.

231. Filippi M, Cercignani M, Inglese M, Horsfield MA, Comi G. Diffusion tensor magnetic resonance imaging in multiple sclerosis. Neurology 56:304-311, 2001.

232. Griffin CM, Chard DT, Ciccarelli O, Kapoor B, Barker GJ, Thompson AI, Miller DH. Diffusion tensor imaging in early relapsing-remitting multiple sclerosis. Multiple Sclerosis 7:290297, 2001.

233. Brooks DJ. Positron emission tomography and single-photon emission computed tomography in central nervous system drug development. NeuroRx 2:226-236, 2005.

234. Devous MD Sr. Single-photon emission computed tomography in neurotherapeutics. NeuroRx 2:237-249, 2005.

235. Sabatini U, Pozzilli C, Pantano P, Koudriavtseva T, Padovani A, Millefiorini E, et al. Involvement of the limbic system in multiple sclerosis patients with depressive disorders. Biol Psychiatry 39: 970-975, 1996.

236. Paulesu E, Perani D, Fazio F, Comi G, Pozzilli C, Martinelli V, et al. Functional basis of memory impairment in multiple sclerosis: a [18F]FDG PET study. Neuroimage 4:87-96, 1996.

237. Bakshi R, Miletich RS, Kinkel PR, Emmet ML, Kinkel WR. High-resolution fluorodeoxyglucose positron emission tomography shows both global and regional cerebral hypometabolism in multiple sclerosis. J Neuroimaging 8:228-234, 1998.

238. Sun X, Tanaka M, Kondo S, Okamoto K, Hirai S. Clinical significance of reduced cerebral metabolism in multiple sclerosis: a combined PET and MRI study. Ann Nucl Med 12:89-94, 1998. 
239. Blinkenberg M, Jensen CV, Holm S, Paulson OB, Sorensen PS. A longitudinal study of cerebral glucose metabolism, MRI, and disability in patients with MS. Neurology 53:149-153, 1999.

240. Blinkenberg M, Rune K, Jensen CV, Ravnborg M, Kyllingsbaek $\mathrm{S}$, Holm S, et al. Cortical cerebral metabolism correlates with MRI lesion load and cognitive dysfunction in MS. Neurology 54:558-564, 2000.

241. Santa Maria MP, Benedict RHB, Bakshi R, Coad ML, Wack D, Burkard R, et al. Functional imaging during covert auditory attention in multiple sclerosis. J Neurol Sci 218:9-15, 2004.

242. Roelcke U, Kappos L, Lechner-Scott J, Brunnschweiler H, Huber $\mathrm{S}$, Ammann W, et al. Reduced glucose metabolism in the frontal cortex and basal ganglia of multiple sclerosis patients with fatigue: a $18 \mathrm{~F}$-fluorodeoxyglucose positron emission tomography study. Neurology 48:1566-1571, 1997.

243. Banati RB, Newcombe J, Gunn RN, Cagnin A, Turkheimer F, Heppner F, et al. The peripheral benzodiazepine binding site in the brain in multiple sclerosis: quantitative in vivo imaging of microglia as a measure of disease activity. Brain 123:2321-2337, 2000.

244. Debruyne JC, Versijpt J, Van Laere KJ, De Vos F, Keppens J, Strijckmans K, et al. PET visualization of microglia in multiple sclerosis patients using [11C]PK11195. Eur J Neurol 10:257264, 2003.

245. Vowinckel E, Reutens D, Becher B, Verge G, Evans A, Owens T, Antel JP. PK11195 binding to the peripheral benzodiazepine receptor as a marker of microglia activation in multiple sclerosis and experimental autoimmune encephalomyelitis. J Neurosci Res 50:345-353, 1997.

246. Yousry TA, Berry I, Filippi M. Functional magnetic resonance imaging in multiple sclerosis. J Neurol Neurosurg Psychiatry 64(Suppl 1):S85-S87, 1998.

247. Gareau PJ, Gati JS, Menon RS, Lee D, Rice G, Mitchell JR, et al. Reduced visual evoked responses in multiple sclerosis patients with optic neuritis: comparison of functional magnetic resonance imaging and visual evoked potentials. Mult Scler 5:161-164, 1999.

248. Lee M, Reddy H, Johansen-Berg H, Pendlebury S, Jenkinson M, Smith $\mathrm{S}$, et al. The motor cortex shows adaptive functional changes to brain injury from multiple sclerosis. Ann Neurol 47: 606-613, 2000.

249. Pantano P, Iannetti GD, Caramia F, Mainero C, Di Legge S,
Bozzao L, et al. Cortical motor reorganization after a single clinical attack of multiple sclerosis. Brain 125:1607-1615, 2002.

250. Parry AM, Scott RB, Palace J, Smith S, Matthews PM. Potentially adaptive functional changes in cognitive processing for patients with multiple sclerosis and their acute modulation by rivastigmine. Brain 126:2750-2760, 2003.

251. Penner IK, Rausch M, Kappos L, Opwis K, Radu EW. Analysis of impairment related functional architecture in MS patients during performance of different attention tasks. J Neurol 250:461472, 2003.

252. Reddy H, Narayanan S, Woolrich M, Mitsumori T, Lapierre Y, Arnold DL, et al. Functional brain reorganization for hand movement in patients with multiple sclerosis: defining distinct effects of injury and disability. Brain 125:2646-2657, 2002.

253. Staffen W, Mair A, Zauner H, Unterrainer J, Niederhofer H, Kutzelnigg A, et al. Cognitive function and fMRI in patients with multiple sclerosis: evidence for compensatory cortical activation during an attention task. Brain 125:1275-1282, 2002.

254. Sweet LH, Rao SM, Primeau M, Mayer AR, Cohen RA. Functional magnetic resonance imaging of working memory among multiple sclerosis patients. J Neuroimaging 14:150-157, 2004.

255. Filippi M, Rocca MA, Mezzapesa DM, Falini A, Colombo B, Scotti G, et al. A functional MRI study of cortical activations associated with object manipulation in patients with MS. Neuroimage 21:1147-1154, 2004.

256. Filippi M, Rocca MA, Mezzapesa DM, Ghezzi A, Falini A, Martinelli V, et al. Simple and complex movement-associated functional MRI changes in patients at presentation with clinically isolated syndromes suggestive of multiple sclerosis. Hum Brain Mapp 21:108-117, 2004.

257. Mackowiak PA, Siegel E, Wasserman SS, Cameron E, Nessaiver MS, Bever CT. Effects of IFN- $\beta$ on human cerebral blood flow distribution. J Interferon Cytokine Res 18:393-397, 1998.

258. Pirko I, Fricke ST, Johnson AJ, Rodriguez M, Macura SI. Magnetic resonance imaging, microscopy, and spectroscopy of the central nervous system in experimental animals. NeuroRx 2:250 264, 2005.

259. Tortorella C, Viti B, Bozzali M, Sormani MP, Rizzo G, Gilardi MF, Comi G, Filippi M. A magnetization transfer histogram study of normal-appearing brain tissue in MS. Neurology 54: 186-193, 2000. 